ARTICLE

Translational Therapeutics

\title{
HAI-2 as a novel inhibitor of plasmin represses lung cancer cell invasion and metastasis
}

\author{
Shang-Ru Wu ${ }^{1}$, Chia-Hao Lin ${ }^{1}$, Han-Po Shih ${ }^{1}$, Chun-Jung Ko ${ }^{1,2}$, Hsin-Ying Lin ${ }^{1}$, Shao-Wei Lan ${ }^{1}$, Hsin-Hsien Lin ${ }^{1}$, Hsin-Fang Tu${ }^{1}$, \\ Chao-Chi Ho ${ }^{3}$, Hsiang-Po Huang ${ }^{4}$ and Ming-Shyue Lee ${ }^{1}$
}

BACKGROUND: Dysregulation of pericellular proteolysis usually accounts for cancer cell invasion and metastasis. Isolation of a cellsurface protease system for lung cancer metastasis is an important issue for mechanistic studies and therapeutic target identification.

METHODS: Immunohistochemistry of a tissue array $(n=64)$ and TCGA database $(n=255)$ were employed to assess the correlation between serine protease inhibitors (SPIs) and lung adenocarcinoma progression. The role of SPI in cell motility was examined using transwell assays. Pulldown and LC/MS/MS were performed to identify the SPI-modulated novel protease(s). A xenografted mouse model was harnessed to demonstrate the role of the SPI in lung cancer metastasis.

RESULTS: Hepatocyte growth factor activator inhibitor-2 (HAl-2) was identified to be downregulated following lung cancer progression, which was related to poor survival and tumour invasion. We further isolated a serum-derived serine protease, plasmin, to be a novel target of HAl-2. Downregulation of HAl-2 promotes cell surface plasmin activity, EMT, and cell motility. HAl-2 can suppress plasmin-mediated activations of HGF and TGF- $\beta 1$, EMT and cell invasion. In addition, downregulated HAI-2 increased metastasis of lung adenocarcinoma via upregulating plasmin activity.

CONCLUSION: HAI-2 functions as a novel inhibitor of plasmin to suppress lung cancer cell motility, EMT and metastasis.

British Journal of Cancer (2019) 120:499-511; https://doi.org/10.1038/s41416-019-0400-2

\section{BACKGROUND}

Non-small cell lung carcinoma (NSCLC) is a primary type of lung cancer with approximately $85 \%$ of the incidence. ${ }^{1}$ The lung cancer patients with metastasis have less than $5 \%$ of the five-year survival rate. ${ }^{2}$ The dysregulation of pericellular proteolysis in the tumour environment often occurs to be a main factor for extracellular matrix (ECM) degradation and cancer cell movement, ultimately contributing to metastasis., ${ }^{3,4}$ Therefore, understanding the molecular mechanisms how metastatic cells abuse pericellular proteolysis will provide insights for the identification of therapeutic targets, as well as development of novel strategies against lung cancer.

Hepatocyte growth factor activator inhibitor-2 (HAl-2) is a biKunitz-type serine protease inhibitor containing two Kunitz domains (KD1 and KD2), first identified in placenta and gastric carcinoma cells with a homology to $\mathrm{HAl}-1$, and has an inhibitory activity against hepatocyte growth factor activator (HGFA) ${ }^{5-7} \mathrm{HAI}-$ 2 also represses the other serine proteases including kallikrein and coagulation factor $\mathrm{Xla}^{8}{ }^{8}$ Several lines of evidence indicate that down-regulation of HAl-2 is involved in cancer progression; for examples, the low expression or genetic silencing of HAl-2 has been found in hepatocellular carcinoma (HCC), prostate cancer, melanoma and gastric cancer. ${ }^{9-12}$ Moreover, HAl-2 is capable of suppressing cancer cell invasion and metastasis, including HCC, melanoma, prostate cancer and endometrial cancer., ${ }^{9,11-13}$ The anti-invasive and anti-metastatic abilities of HAl-2 result from suppression of several serine proteases, such as matriptase and hepsin. ${ }^{11,14}$

The urokinase-plasminogen activation system (UPAS) is a pericellular serine protease cascade that plays crucial roles in ECM remodeling for tissue development and regeneration, even for cancer cell invasion and metastasis. ${ }^{15}$ The components of uPAS include plasminogen and urokinase-type plasminogen activator (uPA), and their cognate Serpin-type inhibitors (PAl-1 and PAI2). ${ }^{15,16}$ During cancer progression, uPA proteolytically activates plasminogen into plasmin and is a primary trigger for the activation of uPAS. ${ }^{17}$ Subsequently, plasmin has a feedforward effect to activate its activator zymogen (pro-uPA), such that a reciprocal activation loop accelerates the plasminogen activation. ${ }^{18}$ In addition to pro-uPA, plasmin has several substrates (fibrin, fibronectin, thrombospondin, laminin, collagenases, growth factors, etc.) to function as a powerful protease for fibrinolysis, tissue remodelling and cancer progression. ${ }^{19}$ Plasmin is often aberrantly turned on in malignancy for invasive tumour growth and dissemination. ${ }^{20}$ The uPAS can activate other pericellular proteases to promote cancer progression. For example, plasmin has been shown to induce the proteolytic activation of metalloproteases-2 and 9 (MMP-2 and MMP-9). ${ }^{21}$ Moreover,

\footnotetext{
${ }^{1}$ Department of Biochemistry and Molecular Biology, College of Medicine, National Taiwan University, R817, 8F, No. 1, Section 1, Jen-Ai Rd., Taipei, Taiwan; ${ }^{2}$ Department of Immunology, the University of Texas MD Anderson Cancer Center, Taipei, Taiwan; ${ }^{3}$ Department of Internal Medicine, National Taiwan University Hospital, College of Medicine, National Taiwan University, Taipei, Taiwan and ${ }^{4}$ Graduate Institute of Medical Genomics and Proteomics, College of Medicine, National Taiwan University, Taipei, Taiwan Correspondence: Ming-Shyue Lee (mslee2006@ntu.edu.tw)
}

Received: 16 May 2018 Revised: 4 December 2018 Accepted: 14 December 2018

Published online: 15 February 2019 

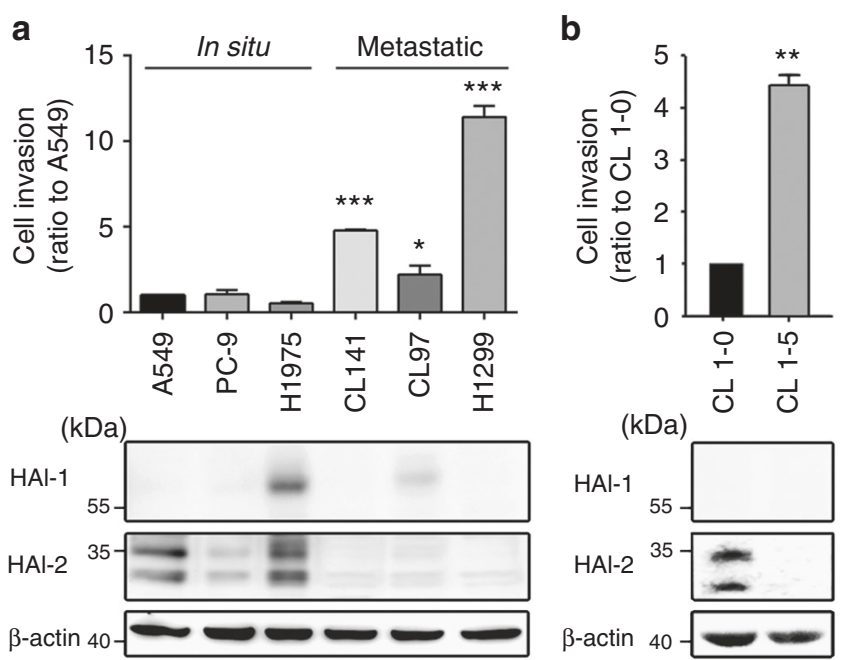
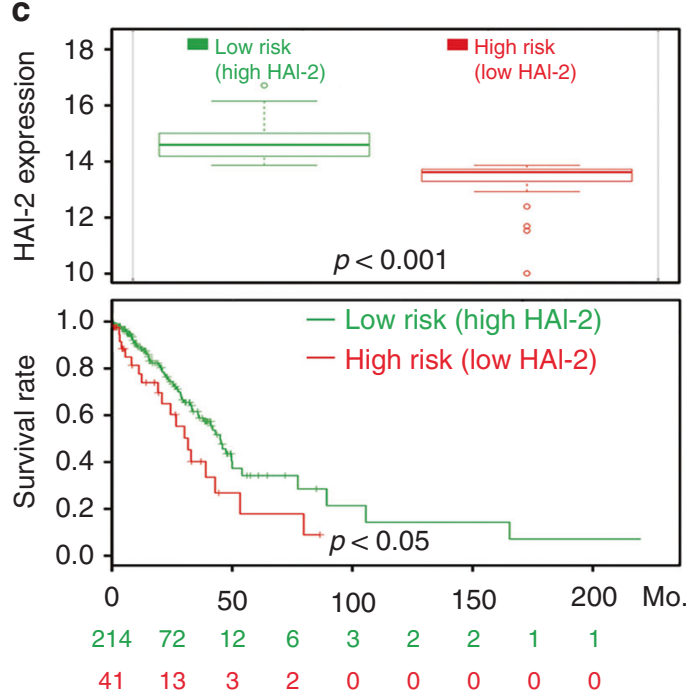

d

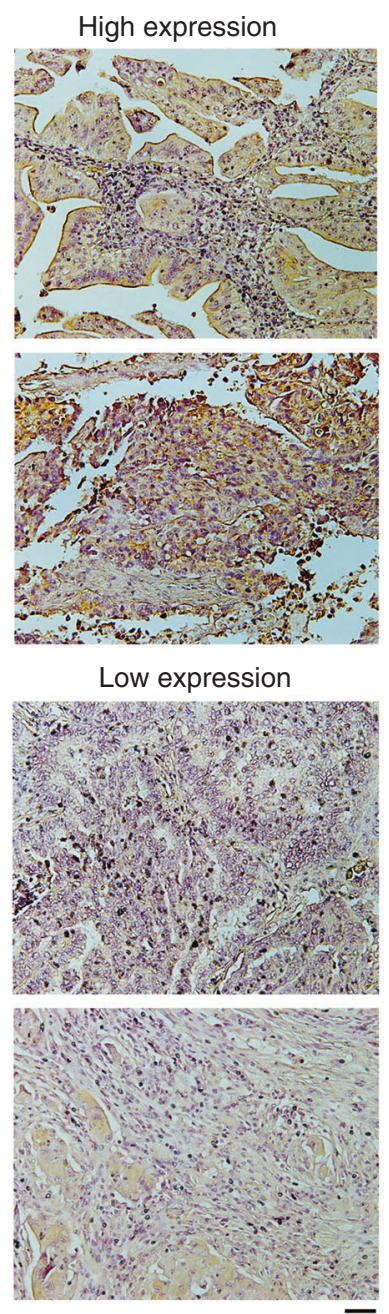

\begin{tabular}{|c|c|c|c|c|}
\hline \multirow[b]{2}{*}{ Characteristics } & \multirow[b]{2}{*}{ Total $N(\%)$} & \multicolumn{2}{|c|}{$\mathrm{HAl}-2$} & \multirow[b]{2}{*}{$\begin{array}{c}P \text { value } \\
\text { (test) }\end{array}$} \\
\hline & & $\begin{array}{c}\text { High } N(\%) \\
28(44)\end{array}$ & $\begin{array}{c}\text { Low } N(\%) \\
36(56)\end{array}$ & \\
\hline \multicolumn{5}{|l|}{ Gender } \\
\hline Male & $40(63)$ & $17(27)$ & $23(36)$ & \multirow{2}{*}{$\begin{array}{c}0.801 \\
\text { (Fisher's test) }\end{array}$} \\
\hline Female & $24(37)$ & $11(17)$ & $13(20)$ & \\
\hline \multicolumn{5}{|l|}{ Age } \\
\hline$<60$ & $42(66)$ & $20(31)$ & $22(35)$ & \multirow{2}{*}{$\begin{array}{c}0.436 \\
\text { (Fisher's test) }\end{array}$} \\
\hline$\geq 60$ & $22(34)$ & $8(13)$ & $14(21)$ & \\
\hline \multicolumn{5}{|l|}{ Tumor invasion } \\
\hline $\mathrm{T} 1+\mathrm{T} 2$ & $49(77)$ & $25(39)$ & $24(38)$ & \multirow{2}{*}{$\begin{array}{c}0.041 \\
\text { (Fisher's test) }\end{array}$} \\
\hline $\mathrm{T} 3+\mathrm{T} 4$ & $15(23)$ & $3(5)$ & $12(18)$ & \\
\hline \multicolumn{5}{|c|}{ Lymph node metastasis } \\
\hline NO & $45(70)$ & $22(34)$ & $23(36)$ & \multirow{2}{*}{$\begin{array}{c}0.272 \\
\text { (Fisher's test) }\end{array}$} \\
\hline $\mathrm{N} 1+\mathrm{N} 2$ & $19(30)$ & $6(9)$ & $13(21)$ & \\
\hline \multicolumn{5}{|c|}{ Distant metastasis } \\
\hline Mo & $62(97)$ & $28(43)$ & $34(54)$ & \multirow{2}{*}{$\begin{array}{c}0.5 \\
\text { (Fisher's test) }\end{array}$} \\
\hline M1 & $2(3)$ & $0(0)$ & $2(3)$ & \\
\hline \multicolumn{5}{|l|}{ Progression } \\
\hline 1 & $38(59)$ & $21(33)$ & $17(26)$ & \multirow{4}{*}{$\begin{array}{c}0.016 \\
\left(\chi^{2} \text { for trend }\right)\end{array}$} \\
\hline II & $15(23)$ & $5(8)$ & $10(15)$ & \\
\hline III & $9(14)$ & $2(3)$ & $7(11)$ & \\
\hline IV & $2(3)$ & $0(0)$ & $2(3)$ & \\
\hline \multicolumn{5}{|c|}{ Early progression } \\
\hline I & $38(59)$ & $21(33)$ & $17(26)$ & \multirow{2}{*}{$\begin{array}{c}0.039 \\
\text { (Fisher's test) }\end{array}$} \\
\hline $\mathrm{II}+\mathrm{III}+\mathrm{IV}$ & $26(41)$ & $7(11)$ & $19(29)$ & \\
\hline \multicolumn{5}{|l|}{ Differentiation } \\
\hline Grade 1 & $2(3)$ & $1(1.5)$ & $1(1.5)$ & \multirow{3}{*}{$\begin{array}{c}0.248 \\
\left(\chi^{2} \text { for trend }\right)\end{array}$} \\
\hline Grade 2 & $36(56)$ & $18(28)$ & $18(28)$ & \\
\hline Grade 3 & $26(41)$ & $9(14)$ & $17(27)$ & \\
\hline
\end{tabular}

UPAS triggers the proteolytic activation of growth factors, including hepatocyte growth factor (HGF) and transforming growth factor- $\beta 1$ (TGF- $\beta 1$ ), to promote malignancy. ${ }^{22-24}$ The expression levels of UPA and UPAR are up-regulated in NSCLC compared to normal tissues. ${ }^{25,26}$ The recent meta-analysis of clinical patients' archival specimens have also suggested that uPA/ uPAR are clinical biomarkers for NSCLC. ${ }^{27}$

Epithelial-mesenchymal transition (EMT) is a programmed process for cell transformation from epithelial to mesenchymal phenotypes, making cell polarity lost and cell motility increased to 
Fig. 1 Down-regulation of HAI-2 is related to the invasion, survival rate and progression of NSCLC. Analyses of the cell invasion and the expression of HAl-1 and HAl-2 in different lung cancer cells (a) and in lowly invasive CL1-0 and highly invasive CL1-5 cells (b). The cells penetrating through the transwells were represented as the migrating or invasive abilities. (mean \pm S.D., $n=3 ;{ }^{*} p<0.05 ;{ }^{* *} p<0.005 ;{ }^{* * *} p<$ 0.001). c Association of survival rate and HAl-2 expression in lung cancer patients. The tissue samples of 255 lung adenocarcinoma patients (SurvExpress, \#13 TCGA database) were divided into High risk and Row risk groups according to the HAI-2 expression levels (upper panel). The survival rates of patients in High risk and Low risk groups were shown in the lower panel. $\mathbf{d}$ Immunohistochemical images of HAl-2 in lung adenocarcinoma (64 cases, LC641, Biomax) are divided into two groups: high HAl-2 expression $(n=28)$ and low HAl-2 expression ( $n=36)$. Scare bar $=100 \mu \mathrm{m}$. Two representative images from each group were shown. e Examination of the associations between HAl-2 protein levels in the IHC images (d) and cancerous characteristics. The significant correlation was statistically determined by Fisher's Exact test or $\chi^{2}$ test

promote metastasis. ${ }^{28}$ During EMT process, the loss of E-cadherin is often accompanied with the up-regulation of mesenchymal neuron cadherin ( $\mathrm{N}$-cadherin) or a cytoskeleton protein Vimentin. ${ }^{29,30}$ EMT program is controlled by specific transcription factors, including Snail, Slug, ZEB (Zinc-E-box binding), and Twist. ${ }^{31}$ Among them, Slug has been reported to play an important role in EMT of NSCLC, promoting cancer cell invasion and drug resistance. $^{32}$

Although HAl-2 was described in many cancers, it still remains elusive if $\mathrm{HAl}-2$ plays a role in lung cancer. In this study, we aimed to investigate the action of $\mathrm{HAl}-2$ on lung cancer progression by identifying HAl-2's target protease(s) and to delineate the mechanism how HAl-2 mediates a protease system in NSCLC. Our findings showed that the expression level of HAI-2 in the archival specimens of lung cancer decreased following the NSCLC progression. HAI-2 overexpression repressed NSCLC cell motility. We identified plasmin(ogen) as an in vivo target of HAI-2, and demonstrated that $\mathrm{HAl}-2$ serves as a novel non-covalent inhibitor for uPAS system by targeting cell-surface plasmin. In addition, HAI2 could regulate the EMT program of NSCLC partly via suppressing the plasmin-mediated activation of pro-HGF and pro-TGF- $\beta$. Our results together highlight the unique role of HAI-2 in NSCLC cell invasion, EMT and metastasis through repressing plasmin.

\section{MATERIALS AND METHODS}

For full descriptions of materials and methods, please see Supplementary Materials and Methods.

\section{Cell Culture}

Human lung adenocarcinoma cell lines were maintained in RPMI 1640 supplemented with $10 \%$ FBS and $1 \%$ L-glutamine.

Lentiviral infection for shRNA interference and overexpression The lentivirus vector system utilised to deliver the shRNA and gene of interest was purchased from the RNAi Core Facility (Academia Sinica, Taipei, Taiwan) The protocols for viral particle production and infection were provided by the RNAi Core Facility.

Recombinant protein purification

GST fusion proteins were produced in BL21 (DE3) E.coli using IPTG induction for $4 \mathrm{~h}$. After cell lysis, the lysates were collected and the GST fusion proteins are purified by affinity columns. The titerless amplification of viral particles and production of recombinant proteins were referred to the previous study. ${ }^{33}$

Animal models and lung metastatic assay

NOD/SCID mice (6 months old) were obtained from the National Laboratory Animal Center (Taipei, Taiwan) and breed following the animal use protocol of IACUC, Academia Sinica. Cells expressing Luc2 gene were suspended at a density of $1 \times 10^{6}$ cells per $100 \mu \mathrm{l}$ OPTIMEM and intravenously injected into the tail vein of each mouse.

\section{Statistics}

The statistical results were calculated from three independent experiments. The significance was determined by one-way ANOVA or Student's $t$-test using Prism 6 software (GraphPad, CA, USA).

\section{RESULTS}

Inverse correlation of HAl-2 expression with lung cancer progression and poor prognosis

To investigate the roles of $\mathrm{HAl}-1$ and $\mathrm{HAl}-2$ in the progression of lung adenocarcinoma, we first analysed the levels of HAl-1 and $\mathrm{HAl}-2$ among six lung adenocarcinoma cell lines and divided them into two groups according to their originality. Among them, A549, PC-9 and H1975 lung adenocarcinoma cells were originally isolated from in situ lung cancer lesions and represent the nonmetastatic group of lung adenocarcinoma; pleural effusionderived cells (CL141 and CL97) and lymph node-derived cells (H1299) are considered to be the metastatic group of lung adenocarcinoma. ${ }^{34-37}$ The results from cell invasion assays showed that the cells in the metastatic group had highly invasive abilities (Fig. 1a, upper panel) and expressed low levels of HAI-2, compared to those in the non-metastatic (in situ) group (Fig. 1a, lower panel). HAl-2 exhibits two major bands by western blot due to its $\mathrm{N}$-glycosylation. ${ }^{38,39} \mathrm{HAl}-1$ expression was only present in H1975 and CL97 cells and showed no correlation with the cell invasion (Fig. 1a, lower panel). Moreover, we examined the status of $\mathrm{HAl}-1$ and $\mathrm{HAl}-2$ in a cell invasion progression model of lung cancer (CL1-0 and CL1-5). Highly invasive CL1-5 lung cancer cells were established and derived from the in situ lung adenocarcinoma cells (CL1-0) after 5-time isolations of invasive cells using Matrigel-coated transwell assays. ${ }^{40}$ We found that highly invasive CL1-5 cells expressed a low HAl-2 level compared to lowly invasive CL1-0 cells, while both cells lacked HAl-1 expression (Fig. 1b). The results together indicate that the expression levels of HAI-2 rather than HAl-1 are inversely correlated with the invasive and metastatic potentials of lung adenocarcinoma cells.

To investigate the correlation of $\mathrm{HAl}-2$ expression levels with the clinical outcome, we utilised the Web resource, SurvExpress, to assess the prognostic significance of $\mathrm{HAl}-2$ in lung adenocarcinoma (TCGA database, $n=255$ ). The population of lung adenocarcinoma in the databank was divided into two groups: low risk and high risk, according to HAl-2 expression levels and Cox model. ${ }^{41}$ The result (Fig. 1c) showed that the high-risk group had a low level of HAl-2 expression (upper panel) with poor prognosis (lower panel) compared to the low-risk group. The data suggest that HAl-2 functions as a tumour suppressor for lung adenocarcinoma. We used immunohistochemical staining $(\mathrm{IHC})$ to analyse HAl-2 protein levels in a lung adenocarcinoma tissue microarray, and classified the data into two groups: low and high expressions of HAl-2 (Fig. 1d). We found that the expression levels of HAl-2 were inversely correlated with high tumour invasion (T1/2 v.s. T3/ 4), cancer progression (stage I, II, III and IV) and early progression (stage I v.s. stage II, III, and IV) (Fig. 1e). These results together indicate that HAl-2 expression is down-regulated following the progression of lung cancer, and the low expression of HAl-2 is associated with poor prognosis.

HAI-2 plays an inhibitory role in NSCLC cell migration and invasion Since the gain of cell motility is a critical step to promote tumour invasive growth and metastasis, ${ }^{42}$ we investigated the role of $\mathrm{HAl}$ 2 in lung adenocarcinoma cell migration and invasion. The results from cell motility assays showed that $\mathrm{HAl}-2$ silencing increased the cell migration and invasion of A549 cells (Fig. 2a). This effect can 
a
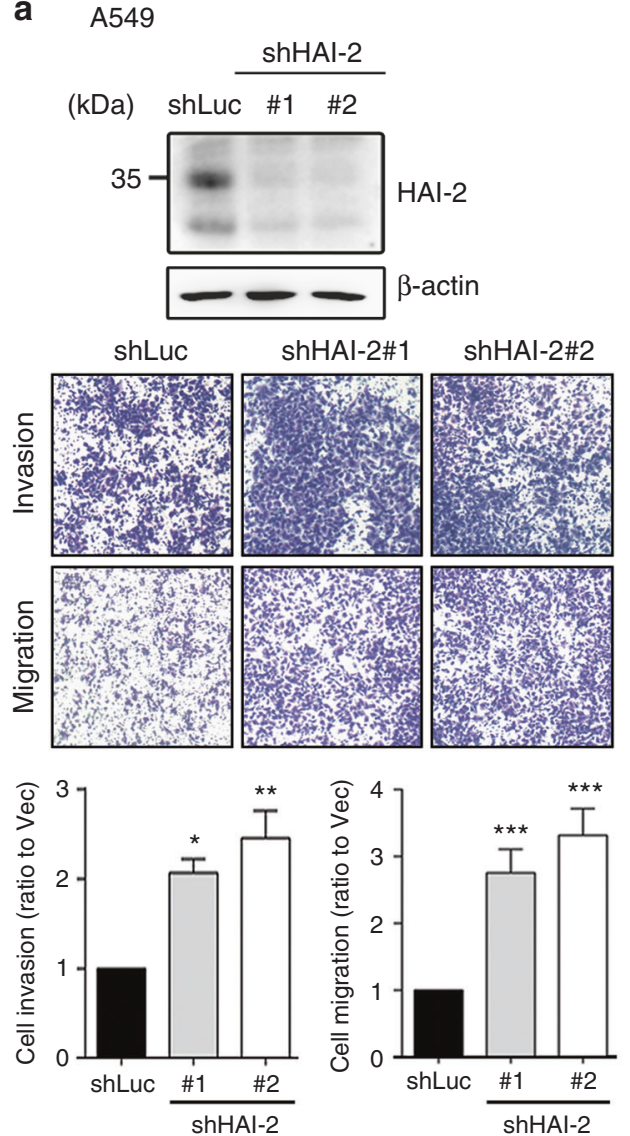

b
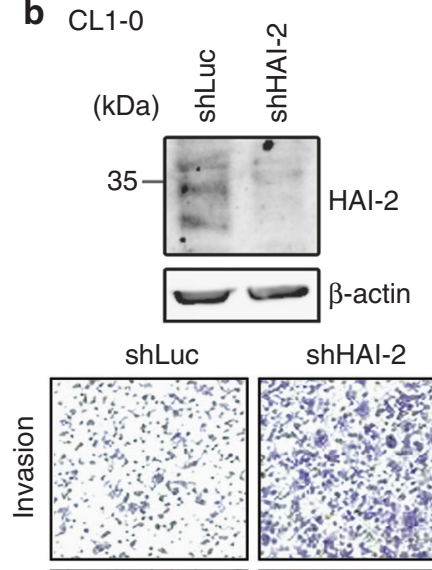

shHAl-2
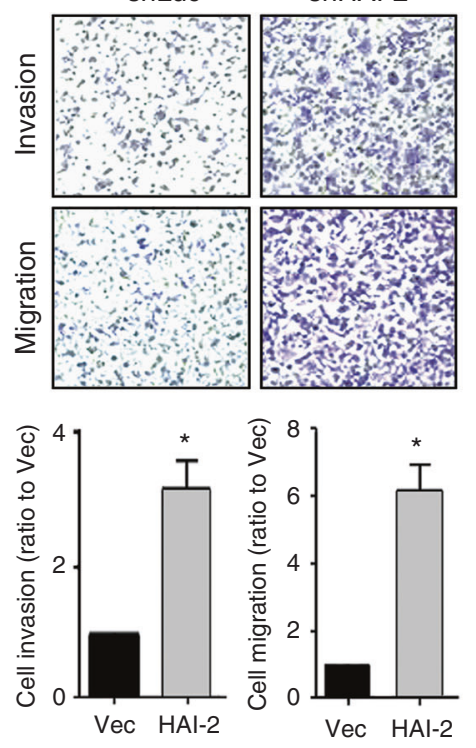

C
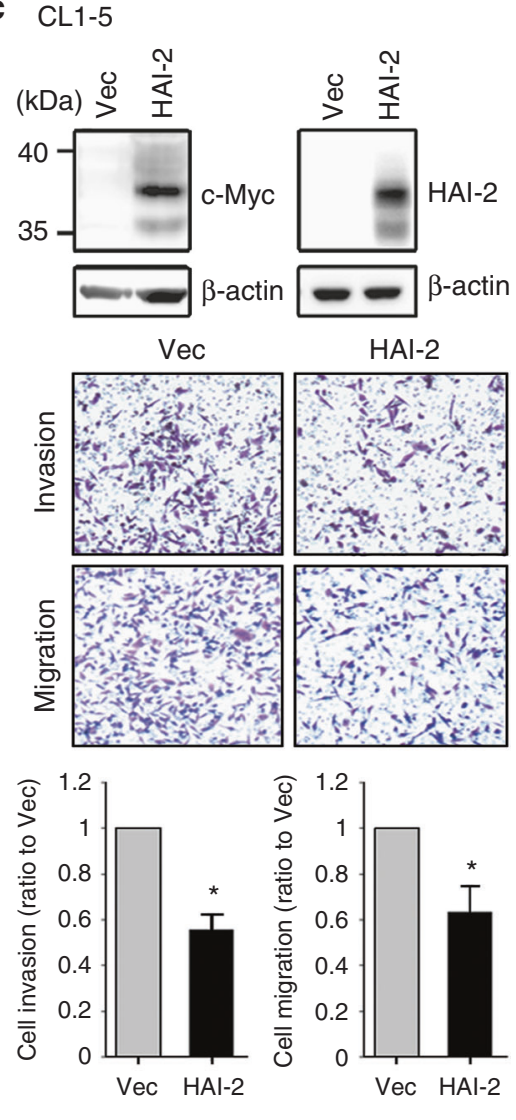

Fig. 2 Role of HAl-2 in lung cancer cell motility. a Effect of HAl-2 knockdown on A549 lung cell migration and invasion. b Effect of HAI-2 silencing on CL1-0 cell migration and invasion. $\mathrm{c}$ Effect of HAl-2 overexpression on CL1-5 cell migration and invasion. CL1-5 cells were stably transfected with HAI-2.Myc construct for cell invasion and migration assays. The cells penetrating the transwells were counted and statistically calculated with a ratio to control cells (mean \pm S.D., $n=3 ;{ }^{*} p<0.05 ;{ }^{* *} p<0.005 ;{ }^{* * *} p<0.001$ ). Magnification, $x 100$

be rescued by re-expression of HAl-2 (Supplementary Figure S1). A similar result was also obtained from $\mathrm{CL} 1-0$ cells that $\mathrm{HAl}-2$ knockdown significantly enhanced the cell migration and invasion (Fig. 2b). On the other hand, overexpression of HAl-2 suppressed the migrating and invasive abilities of highly invasive CL1-5 cells (Fig. 2c). The results together indicate that HAl-2 plays a suppression role in lung cancer cell motility.

Identification of plasminogen as HAl-2's target protease in NSCLC To elucidate the mechanism how HAl-2 inhibited lung adenocarcinoma cell motility, we set up to identify the target protease(s) of HAl-2 in lung adenocarcinoma cells. By using Q-PCR we first investigated if two well-known HAl-2's target proteases (matriptase and hepsin ${ }^{11,14}$ ) were expressed in NSCLC. As shown in Supplementary Figure S2, there was none or little expression of matriptase in NSCLC A549, CL1-0, CL1-5 and H1299 cells. The expression levels of hepsin were low in highly invasive NSCLC CL15 and H1299 cells, compared to lowly invasive A549 and CL1-0 cells. Moreover, according to SurvExpress TCGA database, the results (Supplementary Figure S3) from the statistical analyses showed that a decreased expression level of matriptase was associated with a poor survival rate of lung cancer patients, while there was no association between hepsin expression levels and the patients' survival. The data together suggest that matriptase or hepsin may not be the target of HAI-2 in NSCLC. Thus, we employed GST pulldown and LC/MS-MS analyses to isolate potential target(s) of HAI-2 in NSCLC. The fusion proteins of GST with the Kuntiz domain (KD) 1 and 2 of HAI-2 (GST-KD1 and GSTKD2) were expressed in CL1-5 cells. After GST pulldown, the isolated proteins were separated by SDS-PAGE with CYPRO-Ruby staining (Fig. $3 \mathrm{a}$ ) and then cut out into three fragments ( $A, B$ and $C)$, individually subjected to LC-MS/MS analyses. The identities of these proteins were listed in Fig. 3b. Among them, a serumderived serine protease, plasminogen, received our attention because of its abundant presence in the pulldown products (Fig. 3b, row A). The data revealed that KD1 and KD2 domains of $\mathrm{HAl}-2$ were able to interact with plasminogen from CL1-5 cell lysates as well as in fetal bovine serum (FBS) (Fig. 3c). The immunoprecipitation of $\mathrm{HAl}-2$ from $\mathrm{CL} 1-5$ cell lysates also captured serum-derived plasminogen (Fig. 3d). A similar result (Fig. 3e) was observed that HAl-2 proteins were capable of interacting with both purified human plasminogen (PLG, left panel) and its active enzyme plasmin (PIm, right panel) in A549 cells. In addition, we illustrated the subcellular location of HAl-2 and plasminogen using immunofluorescence and confocal microscopy. The data showed that HAl-2 and plasminogen were colocalised on the cell surface of HAl-2-overexpressing CL1-5 and A549 cells (Fig. 3f). The results collectively indicate that plasmin (ogen) is one of HAl-2's target proteins and both proteins can interact each other at the cell surface in lung adenocarcinoma cells.

$\mathrm{HAl}-2$ represses plasmin activity and plasmin-induced lung cancer cell motility

Since plasmin(ogen) has been shown to play a central role in cancer cell invasion, ${ }^{16}$ we addressed if HAl-2 could repress the proteolytic activity of plasmin or its activator UPA, leading to suppression of NSCLC cell invasion. We inspected the inhibitory 


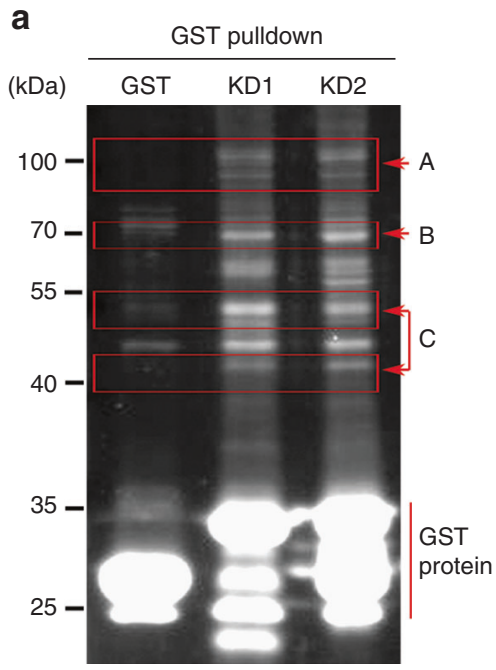

b

\begin{tabular}{|c|c|c|c|c|c|c|}
\hline & \multicolumn{3}{|l|}{ Pulldown of GST-KD1 } & \multicolumn{3}{|l|}{ Pulldown of GST-KD2 } \\
\hline & Protein names & Mass(Da) & Score & Protein names & $\operatorname{Mass}(\mathrm{Da})$ & Score \\
\hline \multirow[t]{6}{*}{ A } & Plasminogen* & 93,894 & 1426 & Plasminogen ${ }^{\star}$ & 93,894 & 2495 \\
\hline & $\alpha$-2-macroglobulin* & 168,953 & 1286 & Serotransferrin* & 79,870 & 2395 \\
\hline & Coatomer subunit $\beta$ & 108,214 & 1150 & $\alpha$-2-macroglobulin* & 168,953 & 1773 \\
\hline & Gelsolin* & 80,966 & 908 & $\alpha$-fetoprotein ${ }^{\star}$ & 70,368 & 1689 \\
\hline & Coatomer subunit $\gamma-1$ & 98,967 & 726 & Gelsolin* & 80,966 & 1425 \\
\hline & $\begin{array}{l}\text { Complement component } \\
\mathrm{C}^{*}\end{array}$ & 96,223 & 685 & Coatomer subunit $\beta$ & 108,214 & 1143 \\
\hline \multirow[t]{5}{*}{ B } & $\begin{array}{l}\alpha-1 \text {-antiproteinase } \\
\alpha-2 \text {-HS-glycoprotein }\end{array}$ & $\begin{array}{l}46,417 \\
39,193\end{array}$ & $\begin{array}{l}722 \\
614\end{array}$ & $\begin{array}{l}\text { Protein disulfide- } \\
\text { isomerase }\end{array}$ & 57,480 & 1929 \\
\hline & Heat shock cognate 71 & 71,424 & 585 & Pyruvate kinase PKM & 58,470 & 1393 \\
\hline & kDa protein* & & & $\alpha$-1-antiproteinase ${ }^{\star}$ & 46,417 & 789 \\
\hline & Pyruvate kinase PKM & 58,470 & 467 & $\alpha$-2-HS-glycoprotein* & 39,193 & 677 \\
\hline & Coatomet subunit $\delta$ & 57,630 & 422 & & & \\
\hline \multirow[t]{3}{*}{ C } & Tubulin $\beta-2 A$ chain & 50,274 & 2078 & Tubulin $\beta-2 A$ chain & 50,274 & 2094 \\
\hline & $\begin{array}{l}\text { Endoplasmic reticulum } \\
\text { resident protein } 44\end{array}$ & 47,341 & 772 & $\begin{array}{l}\text { Endoplasmic reticulum } \\
\text { resident protein } 44\end{array}$ & 47,341 & 1020 \\
\hline & $\begin{array}{l}\text { ATP synthase subunit } \beta \text {, } \\
\text { mitochondrial }\end{array}$ & 59,828 & 352 & Tubulin $\beta-8$ chain & 50,257 & 984 \\
\hline
\end{tabular}

C

(kDa) Input $\frac{\text { GST pulldown }}{\text { GST KD1 KD2 }}$

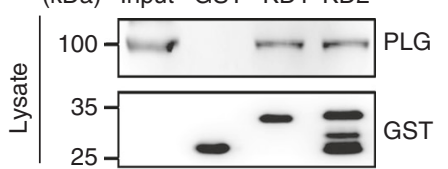

d

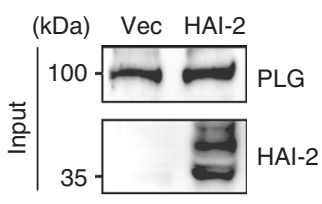

e

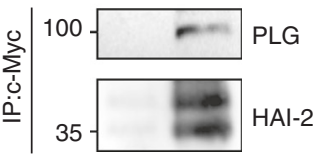

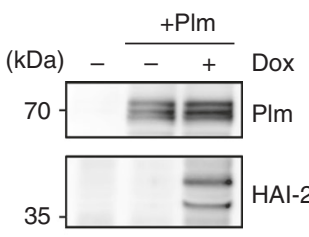

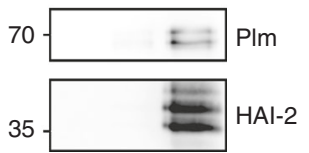

f
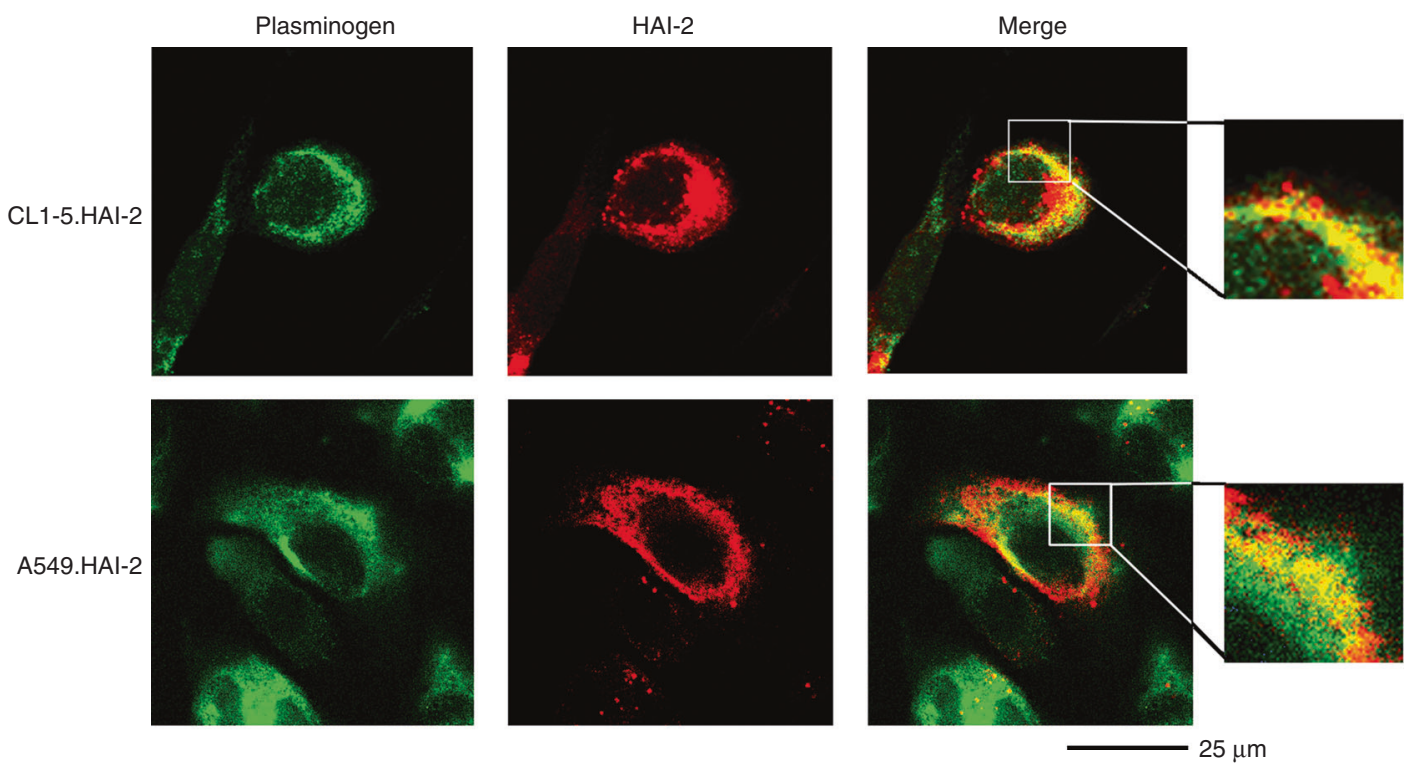

Fig. 3 Identification of HAI-2's associated proteins in lung cancer cells. a SYPRO Ruby-stained image of HAI-2's associated proteins in an acrylamide gel after GST-pulldown and SDS-PAGE assays. The signals were captured by a UVP transilluminator. b The identity list of GSTpulldown proteins in (a) after LC-MS/MS analysis. c Immunoblot analyses of plasminogen after GST-HAI-2's KD pulldown assays using CL1-5 cell lysate and FBS. d Co-immunoprecipitation of HAI-2 and plasminogen in HAl-2-overexpressing CL1-5 cells. HAl-2 proteins were pulled down from cell lysates by anti-c-Myc mAb (9E10). e Interaction of HAl-2 with plasminogen and plasmin using co-immunoprecipitation assays. A549 cells were transduced to carry a HAl-2.tet.aOn gene for HAl-2 overexpression upon doxycycline (Dox) induction. HAI-2 proteins were pulled down by anti-c-Myc mAb (9E10). The eluted samples were subjected to SDS-PAGE and immunoblotting using anti-PLG and anti-HAI-2 pAbs. f Subcellular localisation of plasminogen and HAI-2 using confocal microscopy. The cells were cultured on cell culture slides and immunocytochemically stained with anti-PLG pAb and anti-HAl-2 mAb (DC16), followed by secondary antibodies (Alexa Fluor 488 and 568 ) incubation. The images were captured by a confocal microscope 
a

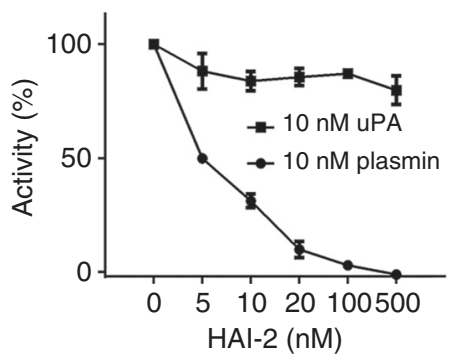

b

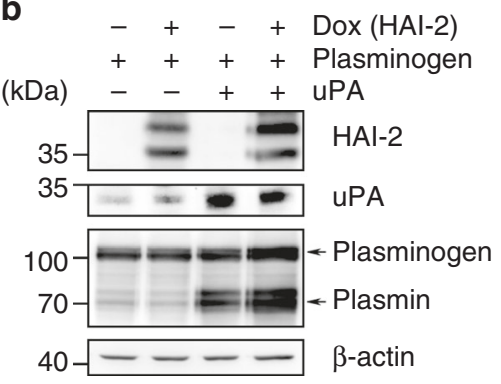

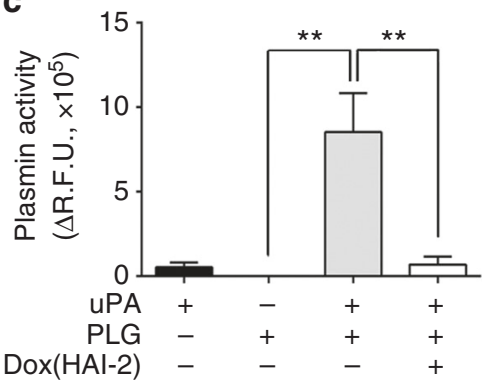

d

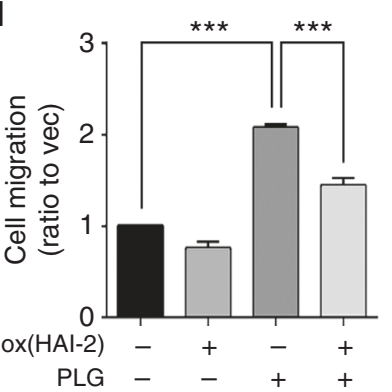

e

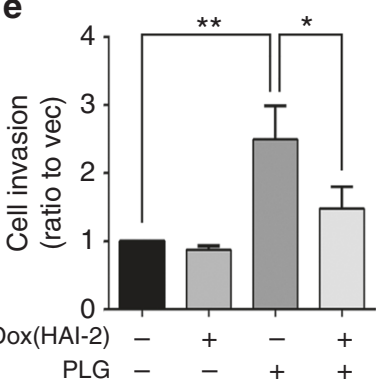

f

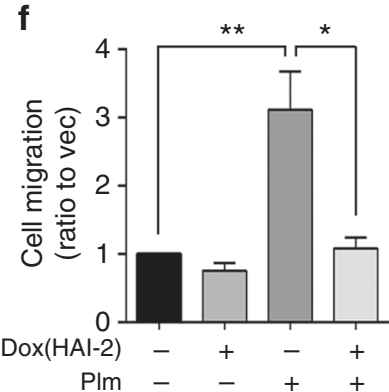

g

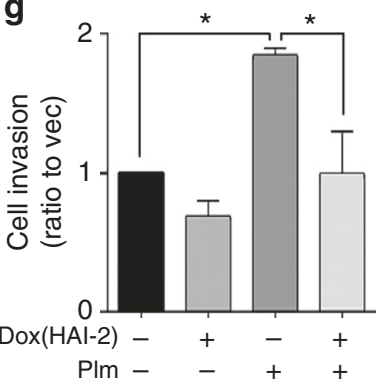

h

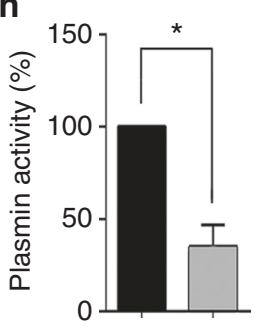

CL1-5 Vec HAI-2

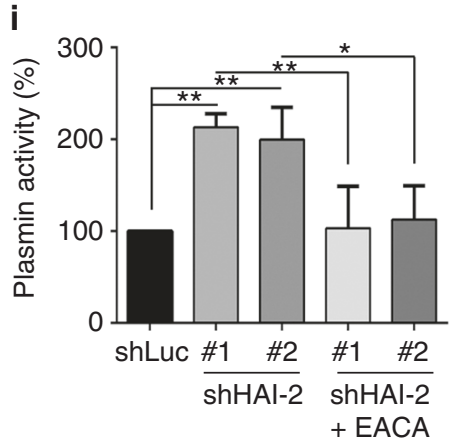

I
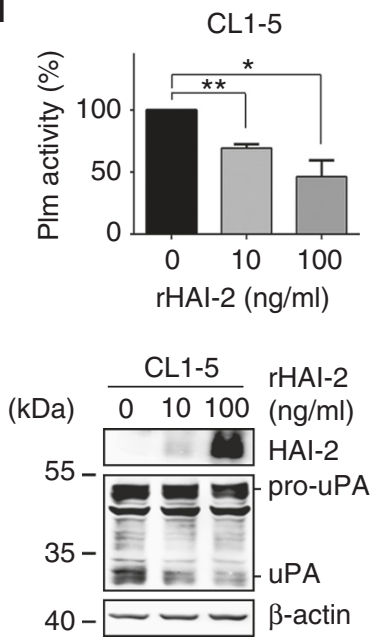

j

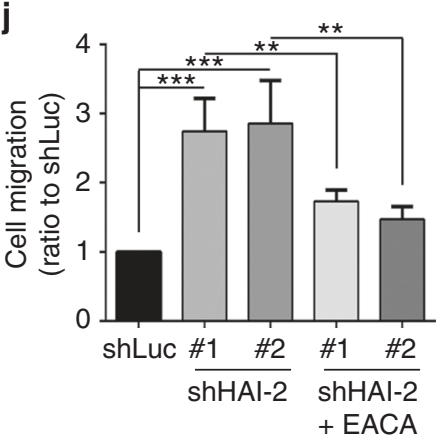

n
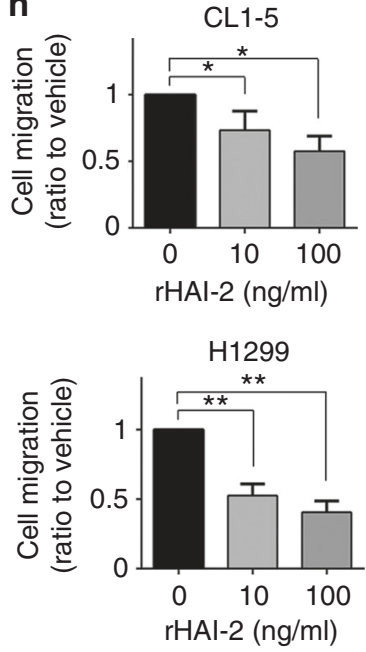

k

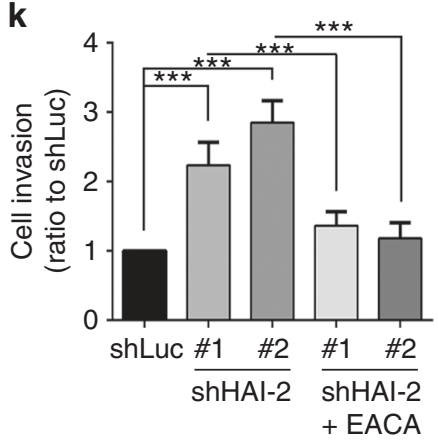

0
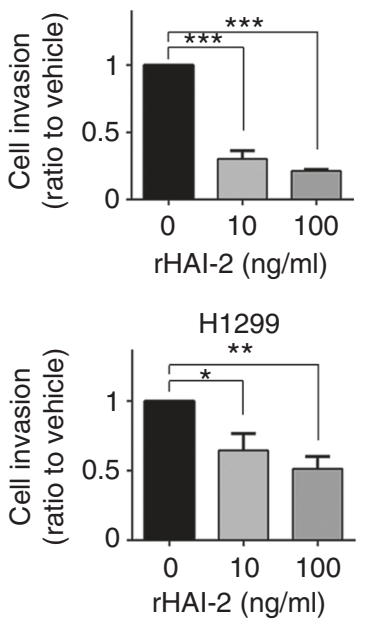

effects of recombinant HAI-2 (rHAl-2) proteins on the proteolytic activities of plasmin and uPA. The rHAl-2 proteins were generated from insect cells and possesses simple glycosylations ${ }^{43}$ that give a single band in western blot. ${ }^{39}$ The results manifested that rHAI-2 proteins were capable of suppressing plasmin proteolytic activity but had no significant effect on uPA (Fig. 4a). Moreover, we found that HAI-2 expression could not repress UPA-induced activation of plasminogen by a proteolytic conversion into plasmin (Fig. 4b). To

mimic the plasminogen activation system on the cell surface, we sequentially added purified human uPA and plasminogen into A549 cell cultures with or without $\mathrm{HAl}-2$ overexpression. The results showed that the addition of uPA turned on the proteolytic activity of plasminogen, and HAl-2 was able to suppress the proteolytic activity of plasmin which was activated by uPA (Fig. 4c). The data together indicate that $\mathrm{HAl}-2$ directly represses plasmin activity rather than $\mathrm{UPA}$. 
Fig. 4 HAI-2 represses plasmin proteolytic activities and decreases lung cancer cell motility. a rHAl-2 inhibits the proteolytic activity of plasmin rather than UPA. Human active UPA and plasmin were incubated with rHAI-2 at the indicated concentrations. The artificial substrate (ALK-AMC for plasmin; GGR-AMC for UPA) were added to measure the protease activities (mean \pm S.D., $n=3$ ) b Examination of HAI-2 role in uPAmediated plasminogen activation. After Dox induction for HAl-2 expression, cells were treated with or without $1 \mu \mathrm{g} / \mathrm{ml}$ human active uPA and $10 \mu \mathrm{g} / \mathrm{ml}$ human plasminogen. After $6 \mathrm{~h}$, cell lysates were harvested for SDS-PAGE and immunoblotting. c Inhibitory effect of HAl-2 on the proteolytic activities of UPA-mediated plasminogen activation. After Dox induction for HAl-2 expression, $100 \mathrm{ng}$ of human active uPA were added into cells and followed by adding $1 \mu \mathrm{g}$ human plasminogen. The artificial substrate (ALK-AMC) was used to measure plasmin activities. (D/E) HAl-2 overexpression suppresses plasminogen-induced cell migration (d) and cell invasion (e). After serum starvation and EACA treatment, the cells were seeded to the transwells in the presence and absence of $10 \mu \mathrm{g} / \mathrm{ml}$ plasminogen (PLG) for cell migration and invasion assays. $\mathbf{f} / \mathbf{g ~ H A l - 2}$ overexpression suppresses plasmin-induced cell migration in the presence/absence of plasmin (PIm). $\mathbf{h}$ Analysis of cellsurface plasmin activity in HAl-2-overexpressing CL1-5 cells. i Analysis of cell-surface plasmin activity in HAl-2-knockdown A549 cells. The equal volume of $10 \mu \mathrm{M}$ artificial substrate (ALK-AMC) was mixed with $100 \mu \mathrm{l}$ of cell suspension to measure the cell-based plasmin activities. (mean \pm S.D., $\left.n=3 ;{ }^{*} p<0.05\right)$. $\mathbf{j} / \mathbf{k}$ Effect of plasmin inhibition on HAl-2 silencing-induced A549 cell migration (j) and cell invasion (k). $\mathbf{l} / \mathbf{m}$ Effects of recombinant HAl-2 proteins on the cell-surface plasmin proteolytic activity in CL1-5 (I) and (m) H1299 lung cancer cells. $\mathbf{n} / \mathbf{o}$ Effects of rHAI-2 on the migration (n) and invasion (o) of CL1-5 and H1299 cells. The cells passing through transwells were statistically calculated and represented as mean \pm S.D. $\left(n=3 ;{ }^{*} p<0.05 ;{ }^{* *} p<0.005 ;{ }^{* * *} p<0.001\right)$

To examine if $\mathrm{HAl}-2$-repressed cell migration and invasion were through inhibition of plasmin, we analysed the role of HAI-2 in plasmin(ogen)-induced A549 cell migration and invasion. The results showed that the addition of plasminogen or plasmin promoted the cell migration and invasion, and HAl-2 overexpression repressed plasminogen/plasmin-induced cell motility (Figs. 4d-g; Supplementary Figure S4). The added plasminogen was converted to plasmin by A549 cells in a time-kinetic manner and be up to approximately $97 \%$ activation of plasminogen to plasmin within $8 \mathrm{~h}$. (Supplementary Figure S5). HAl-2 overexpression significantly reduced the cell-surface plasmin activity in CL1-5 cells (Fig. 4h), while HAl-2 silencing increased the proteolytic activity of cell-surface plasmin in A549 cells (Fig. 4i). A plasmin inhibitor, EACA (Epsilon-aminocaproic acid ${ }^{44}$ ), ably blocked HAl-2 knockdown-induced plasmin activity (Fig. 4i), the lung adenocarcinoma cell migration and invasion (Figs. $4 \mathrm{j}$, k; Supplementary Figure S6). Since pro-uPA can be proteolytically activated by plasmin, ${ }^{18} \mathrm{HAl}-2$ overexpression reduced the levels of plasmin and active UPA in CL1-5 cells (Supplementary Figure S7A, left panel) and $\mathrm{HAl}-2$ silencing increased the levels of plasmin and active uPA in A549 cells (Supplementary Figure S7A, right panel). Moreover, the treatment of EACA subsided cell-surface plasmin and decreased active uPA to basal levels (Supplementary Figure S7A, right panel). The results together indicate that HAI-2 inhibits cellsurface plasmin, leading to reducing active UPA and the reciprocal activation of plasminogen activation system (PAS). In addition, since metalloproteases-2 and 9 (MMP-2 and MMP-9) can be activated by plasmin, ${ }^{21,45}$ the data from zymography revealed a strong MMP-9 gelatinolytic activity in CL1-5 cells, and HAI-2 overexpression dramatically reduced the protease activity ( 82 $\mathrm{kDa}$, Supplementary Figure S7B, left panel). HAl-2 silencing increased the gelatinolytic activities of MMP-2 in A549 cells, and the treatment of EACA subsided the MMP-2 activity which was induced by HAl-2 silencing ( $62 \mathrm{kDa}$, Supplementary Figure S7B, right panel). These results together indicate that $\mathrm{HAl}$-2-repressed NSCLC cell motility, pro-uPA activation and MMP-2/9 activities are through suppressing cell-surface plasmin.

Recombinant $\mathrm{HAl}-2$ proteins repress cell-surface plasmin activities, NSCLC cell migration and invasion

Purified recombinant $\mathrm{HAl}-2$ (rHAl-2) proteins containing the extracellular region of $\mathrm{HAl}-2$ had been shown to repress prostate and breast cancer cell invasion. ${ }^{7,39}$ We assessed the effects of rHAl2 proteins on the cell-surface plasmin, UPA and cell motility of highly invasive CL1-5 and H1299 NSCLC. The results showed that rHAl-2 proteins were able to inhibit the cell-surface plasmin activities and UPA activation of CL1-5 (Fig. 4I) and H1299 cells (Fig. $4 \mathrm{~m}$ ) in a dose-dependent manner. rHAl-2 also dramatically reduced the migratory (Fig. $4 \mathrm{n}$ ) and invasive capabilities (Fig. 4o) of CL1-5 and H1299 cells (Supplementary Figure S8). The findings together indicate that rHAI-2 proteins with HAI-2's extracellular region are capable of suppressing the cell-surface plasmin activities, UPA activation and NSCLC cell motility.

HAl-2 inhibits an EMT-like transition of NSCLC through suppression of plasmin/uPA, HGF and TGF $\beta 1$ signalling

The highly invasive CL1-5 cells exhibit a low level of E-cadherin compared to their primary, lowly invasive CL1-0 cells. ${ }^{46}$ We also observed that CL1-5 cells had a spindle-like phenotype compared to epithelial-like CL1-0 cells, and HAl-2 overexpression restored the phenotype of CL1-5 cells to CL1-0 cells (Fig. 5a). The inspection of epithelial/mesenchymal markers showed that CL1-5 cells had an up-regulation of $\mathrm{N}$-cadherin and Vimentin (two mesenchymal cell markers), and a decreased level of E-cadherin (an epithelial biomarker), indicating that CL1-5 cells exhibit a mesenchymal phenotype (Fig. 5b). Interestingly, HAI-2 overexpression restored the expression of E-cadherin and down-regulated $\mathrm{N}$-cadherin and Vimentin, suggesting that $\mathrm{HAl}-2$ can promote the mesenchymal epithelial transition (MET) of lung cancer cells (Fig. 5c). We analysed the gene expression levels of four EMT-related transcription factors (Slug, Snail, Twist and ZEB2) using Q-PCR in CL1-5, CL1-0 and HAl-2-knockdown A549 cells. The data showed that only Slug dramatically increased in CL1-5 cells compared to CL1-0 cells (Supplementary Figure S9A) and HAl-2 silencing enhanced Slug expression in A549 cells (Supplementary Figure S9B). Interestingly, HAl-2 overexpression pushed the transition of CL15 cells from mesenchymal to epithelial characteristics (an increase of E-cadherin and decreased levels of $\mathrm{N}$-cadherin, Vimentin and Slug) (Fig. 5c). Since the HGF/c-Met signal pathway has been reported to mediate $\mathrm{EMT}^{47}$ the protein and phosphorylation levels of c-Met were up-regulated in CL1-5 cells and downregulated after $\mathrm{HAl}-2$ overexpression in the cells (Fig. $5 \mathrm{c}$, lower panel). HAI-2 silencing also promoted EMT-like transitions of A549 cells, including morphological alterations, cell scattering (Fig. $5 \mathrm{~d}$ ), down-regulation of E-cadherin, activation of UPA, and upregulation of $\mathrm{N}$-cadherin, Vimentin, Slug and c-Met signalling (Fig. 5e). The results together suggest that $\mathrm{HAl}-2$ is a regulator of the MET of NSCLC.

To investigate whether plasmin(ogen) was involved in HAl-2mediated MET of NSCLC, A549 cells were treated with or without plasminogen in the presence or absence of doxycycline for HAl-2 overexpression. The addition of plasminogen promoted the morphological changed to a spindle-like phenotype with increasing cell protrusions (Fig. 5f), while HAl-2 expression attenuated the effect of plasminogen on the biological events of NSCLC (Fig. $5 \mathrm{~g}$ ). The conversion of plasminogen to plasmin occurred after its addition into cell cultures (Figs. $4 \mathrm{~b}$ and $5 \mathrm{~g}$ ). The administration of plasminogen dramatically up-regulated Vimentin while had less effects on E-cadherin, N-cadherin or Slug (Fig. 5g). HAl-2 overexpression subsided the levels of plasminogen-increased 


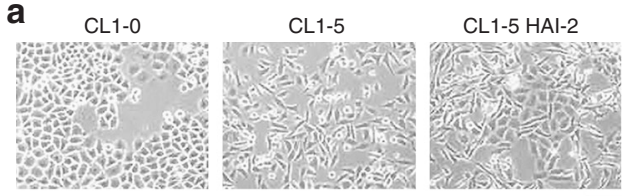

b

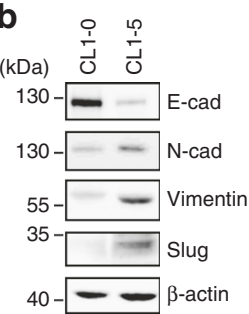

f ${ }_{\text {A549 }}$
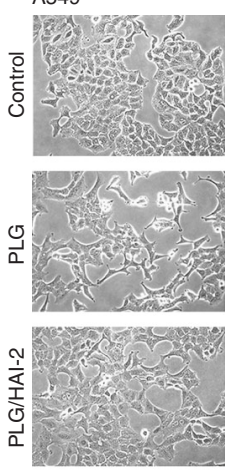

j

++ pro-HGF

-++ Plasmin

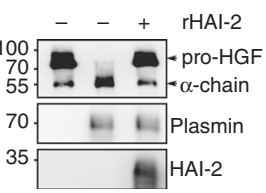

k

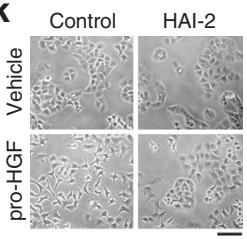

o

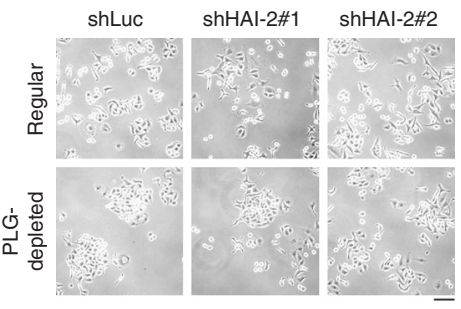

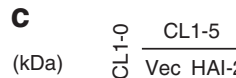

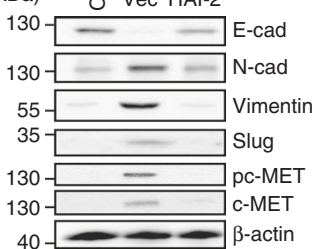

g

- + + HAl-2 (Dox)

(kDa) -++ PLG
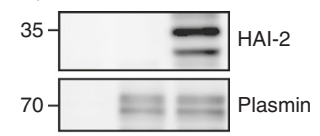

$130-\longdiv { - }$ E-cad

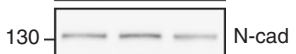

$55--$ Vimentin

35

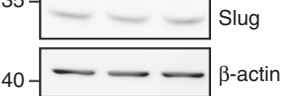

I

(kDa) $-+-\quad+\begin{aligned} & \text { Dox } \\ & \text { (HAl-2) }\end{aligned}$

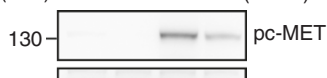

$130-\square$ C-MET

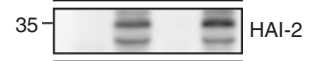

$130-\ldots \ldots$ E-cad

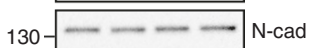

$55-\ldots$ Vimentin

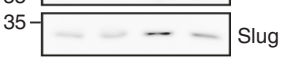

40

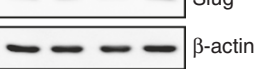

d
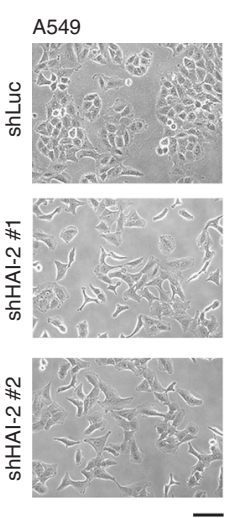

h
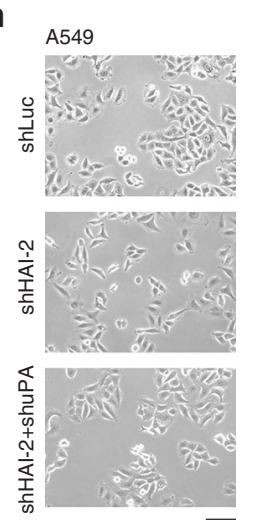

m
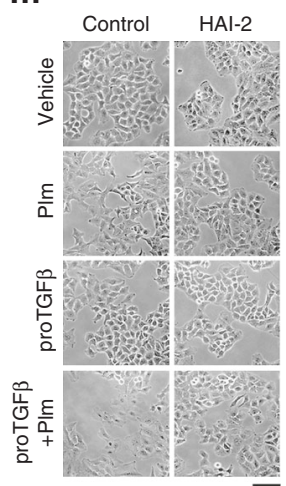

p

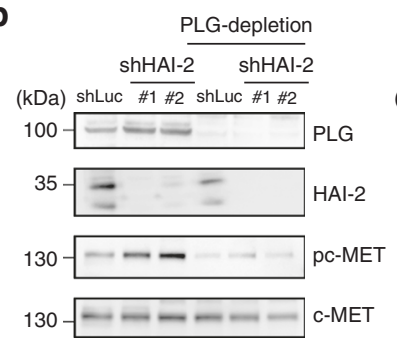

e

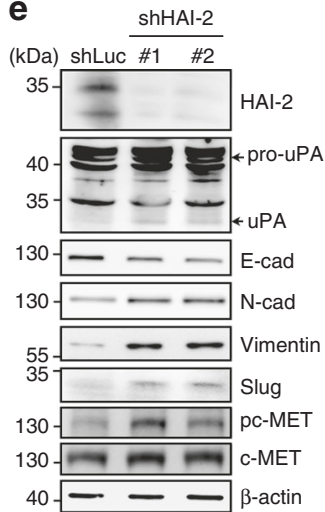

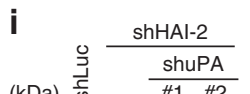

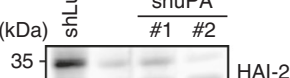

$35-\square$ HAl-2

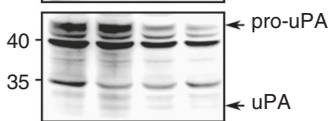

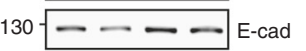

$130=$ N-cad

${ }_{55}-\quad-\quad-$ Vimentin

$35-\ldots$ slug

$40--1-\beta$-actin

n $\ldots+-++++$ pro-TGF

$-+-+-+++\operatorname{Dox}(\mathrm{HAl}-2)$

(kDa) $-+++\ldots++$ Plasmin

$35-\quad=\quad$ HAl-2

$70-\square \mathrm{PIm}$

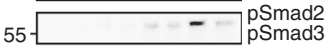

55 추루루룰요 Smad2

130 - - E-c-cad

$130-\ldots \cdots \cdots-c-c a d$

$55-\ldots$ Vimentin

$35+-\cdots$ slug

$40--\cdots--a c t i n$

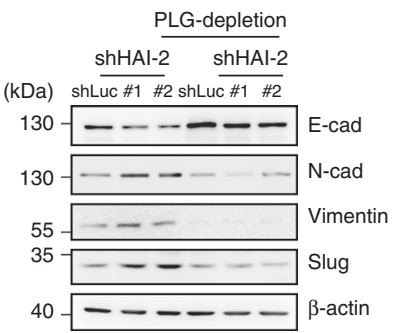

Vimentin (Fig. 5g). These results together indicate that HAl-2 can repress plasminogen/plasmin-induced morphological alterations and Vimentin expression in NSCLC.

Since knockdown of HAI-2 increased the levels of UPA and the EMT of NSCLC, we examined whether UPA played a role in promoting the EMT of NSCLC. shRNA approaches were employed to knock down HAl-2 or UPA in A549 cells. The results (Fig. 5h) showed that $\mathrm{HAl}-2$ knockdown promoted the cell scattering, and uPA silencing attenuated the degree of cell scattering in HAl-2-knockdown A549 cells. Similar to the results in Fig. 5e, HAl-2 knockdown decreased the protein levels of $\mathrm{E}$-cadherin and up-regulated N-cadherin, Vimentin, and Slug in A549 cells (Fig. 5i). Silencing of uPA was able to revert the HAI-2 knockdown-induced changes on E-cadherin, N-cadherin, 
Fig. 5 HAI-2-mediated mesenchymal epithelial transition of NSCLC via repressing plasmin activity, HGF/c-Met and TGF $\beta$ signalling. a The morphology of CL1-0, CL1-5, and HAI-2-overexpressing CL1-5 cells taken by a microscope. Scale bar = $100 \mu \mathrm{m}$. b/c lmmunoblots of epithelial/ mesenchymal cell biomarkers, phospho-c-Met and c-Met in CL1-0, CL1-5 and HAl-2-overexpressing CL1-5 cells. d The morphology of HAI-2 knockdown (shHAl-2 \#1 and \#2) and control (shLuc) A549 cells was pictured by a microscope. Scale bar $=100 \mu \mathrm{m}$. e Immunoblots of HAl-2, uPA, epithelial mesenchymal biomarkers, phospho-c-Met and c-Met in HAl-2 knockdown (shHAl-2 \#1 and \#2) and control (shLuc) A549 cells. f The morphology of A549 cells after the treatment of $10 \mu \mathrm{g} / \mathrm{ml}$ plasminogen or $1 \mu \mathrm{g} / \mathrm{ml}$ doxycycline in a serum-free culture condition for $48 \mathrm{~h}$. Scale bar $=100 \mu \mathrm{m}$. g Immunoblots of HAl-2, plasmin, epithelial/mesenchymal biomarkers in A549 cells after the treatment. $\mathbf{h}$ The morphology of HAI-2 or uPA-knockdown A549 cells. Scale bar $=100 \mu \mathrm{m}$. i Immunoblots of HAl-2, uPA, and epithelial/mesenchymal biomarkers in HAl-2- or uPA-knockdown A549 cells. $\mathbf{j}$ Effect of plasmin and rHAl-2 on pro-HGF. $100 \mathrm{nM}$ of pro-HGF, plasmin and rHAl-2 proteins were incubated in PBS for $2 \mathrm{~h}$. Samples were then analysed by immunoblotting using anti-HGF ( $\alpha$-chain specific), anti-plasmin(ogen), and anti-HAl-2 pAbs. k The morphology of A549 cells after the treatment of $100 \mathrm{ng} / \mathrm{ml}$ pro-HGF or HAI-2 overexpression (Dox) for $48 \mathrm{~h}$ (scale bar $=100 \mu \mathrm{m}$ ). I Effect of pro-HGF and HAl-2 on the c-Met signalling and epithelial/mesenchymal markers. $\mathbf{m}$ The morphology of A549 cells after the treatment of plasmin, pro-TGF $\beta 1$ or HAI-2 overexpression (Dox) for $48 \mathrm{~h}$. Scale bar $=100 \mu \mathrm{m}$. $\mathbf{n}$ Immunoblots of HAl-2, plasmin, Smad2/3 signalling, and epithelial/mesenchymal biomarkers in the presence or absence of pro-TGF $\beta 1, \mathrm{HAl}-2$ or plasmin in A549 cells. o The morphology of HAI-2 knockdown (shHAl-2 \#1 and \#2) and control (shLuc) A549 cells in the culture media with normal or plasminogen-depleted FBS (scale bar = $100 \mathrm{~nm}$ ). p Immunoblot analyses of plasminogen, HAl-2, c-Met signalling, and epithelial/mesenchymal biomarkers in HAl-2 knockdown (shHAI-2 \#1 and \#2) and control (shLuc) A549 cells with regular or plasminogen-depleted FBS

Vimentin and Slug in the cells (Fig. 5i). The results together indicate that UPA plays an important role in the EMT of NSCLC when HAI-2 is down-regulated.

Since PAS plays a critical role in hepatocyte growth factor (HGF) activation $^{48}$ that promotes the EMT of NSCLC, ${ }^{49}$ we examined if $\mathrm{HGF} / \mathrm{c}-\mathrm{Met}$ signalling was involved in HAl-2-mediated MET of NSCLC. The data of the in vitro assay showed that active plasmin was able to proteolytically cleave pro-HGF (indicated by a release of the a-chain of HGF), and recombinant HAl-2 (rHAl-2) proteins ably inhibited plasmin function for the proteolytic cleavage of proHGF to HGF (Fig. 5j). In the presence of pro-HGF under a serumfree condition for $48 \mathrm{~h}$, the morphology of A549 cells was elongated and overexpression of $\mathrm{HAl}-2$ suppressed pro-HGFinduced morphological alteration of A549 cells (Fig. 5k). c-Met signalling was highly induced by the addition of pro-HGF into the cells, and the HGF-induced c-Met signalling was attenuated upon HAl-2 overexpression (Fig. 5l). HGF-induced c-Met signalling down-regulated E-cadherin and up-regulated Vimentin and Slug, but did not considerably change N-cadherin; all of HGF/c-Metaltered events were reverted after HAl-2 overexpression (Fig. 5I). The results together indicate that HAl-2 promotes the MET of NSCLC in part via suppressing the plasmin-mediated proteolysis of pro-HGF and c-Met signalling.

In addition to HGF, TGF- $\beta 1$ has been shown to be another potent inducer for the EMT of cancers. ${ }^{50,51}$ Since it has been documented that plasmin is involved in TGF- $\beta 1$ activation, ${ }^{24,52}$ we investigated whether the HAI-2-plasmin axis could modulate TGF$\beta 1$ activation for the EMT of NSCLC. To assess the role of the HAI-2plasmin axis in TGF- $\beta 1$ activation of NSCLC, the morphology of A549 cells and TGF- $\beta$ signalling were examined after the treatment of pro-TGF- $\beta 1$ or plasmin. As shown in Fig. $5 \mathrm{~m}$, proTGF- $\beta 1$ alone did not significantly change the morphology of A549 cells. The co-treatment of pro-TGF- $\beta 1$ and plasmin transformed A549 epithelial cells into a spindle-like, mesenchymal phenotype. HAI-2 overexpression attenuated plasmin-TGF- $\beta 1$ induced morphological change of NSCLC (Fig. $5 \mathrm{~m}$ ). Activation of pro-TGF- $\beta 1$ by plasmin was indicated by the increased phosphorylation levels of Smad2, a downstream effector of the TGF- $\beta$ signal pathway (Fig. $5 \mathrm{n}$ ). HAl-2 overexpression ably subsided the role of plasmin in the activation of pro-TGF- $\beta 1$ (Fig. $5 n$ ). Similarly, the cotreatment of plasmin and pro-TGF- $\beta 1$ dramatically decreased Ecadherin and up-regulated Vimentin and Slug, while the HAl-2 overexpression suppressed the effects of plasmin and pro-TGF- $\beta 1$ on the above biological events (Fig. $5 n$ ). The plasminogen depletion reduced the induction effects of $\mathrm{HAl}-2$ knockdown on NSCLC A549 cell scattering (Fig. 5o). The EMT characteristics in HAl-2-silencing NSCLC were reverted after plasminogen was depleted (Fig. $5 p$ ). The results together suggest that plasmin is an important protease in $\mathrm{HAl}$-2-silencing-induced EMT of NSCLC, and indicate that $\mathrm{HAl}-2$ plays an inhibitory role in plasmin-induced activation of pro-HGF and pro-TGF- $\beta 1$ for the EMT of NSCLC.

Knockdown of HAl-2 promoted lung cancer metastasis and EMT in a xenografted mouse model

To assess the roles of HAI-2 in NSCLC metastasis, we intravenously injected HAl-2-knockdown A549 cells and control cells into immunodeficient mice and analysed tumour formation in the mouse lungs. The result showed that HAl-2-knockdown induced A549 cell colonisation in the lungs after tail vein injection, compared to control cells, indicating that down-regulation of HAI2 increased the lung metastatic ability of NSCLC (Fig. 6a-d). Moreover, the tumours with $\mathrm{HAl}-2$ knockdown possessed higher plasmin activities than control tumours and normal tissues (Fig. 6e, f). To investigate whether the down-regulation of HAl-2 could promote the EMT of the lung cancer cells in metastatic lesions, we analysed the epithelial and mesenchymal markers in the sections of lung metastatic tumours. The data revealed that the tumour lesions with $\mathrm{HAl}-2$ knockdown exhibited a mesenchymal phenotype (a decreased level of E-cadherin and increased levels of $\mathrm{N}$ cadherin and Vimentin), compared to control (Fig. $6 \mathrm{~g}, \mathrm{~h}$ ). These findings together indicate that down-regulation of $\mathrm{HAl}-2$ increases the EMT of NSCLC and metastasis, at least in part via an increase of plasmin activities.

\section{DISCUSSION}

Dysregulation of pericellular proteolysis has been implicated in cancer progression and metastasis. In this study, we found that a membrane-anchored serine protease inhibitor-HAl-2 was downregulated in highly invasive NSCLC. We identified plasmin to be a target protease of HAl-2 in NSCLC. A novel molecular mechanism was shown that HAl-2 serves as a novel non-covalent inhibitor of plasmin and suppresses the protease-induced activations of proHGF, pro-TGF- $\beta 1$ and MMP-2/9 as well as ECM degradation, leading to reducing lung cancer cell motility, EMT, and metastasis (Fig. 6i). The findings indicate that the down-regulation of HAI-2 during the NSCLC progression promotes cell invasion and metastasis via an elevation of plasmin activity, activations of pro-HGF and pro-TGF- $\beta 1$, and promotion of EMT.

Given that $\mathrm{HAl}-2$ has a broadly inhibitory spectra against pericellular proteases, ${ }^{8}$ down-regulation of HAI-2 may result in the aberrant activations of cell-surface protease cascades, culminating in a proteolytic storm and tumour cell dissemination. For example, $\mathrm{HAl}-2$ can suppress prostate cancer cell invasion, tumour growth and metastasis via targeting a membrane-anchored serine protease matriptase. ${ }^{11}$ However, NSCLC showed none or few expressions of matriptase (Supplementary Figure S2 \& S10). The other target of HAl-2, hepsin, also promotes cancer 
a

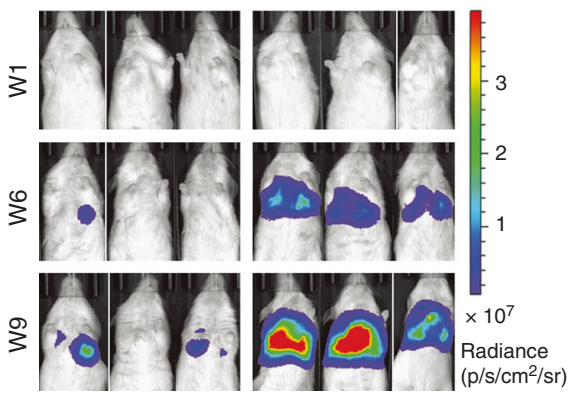

C

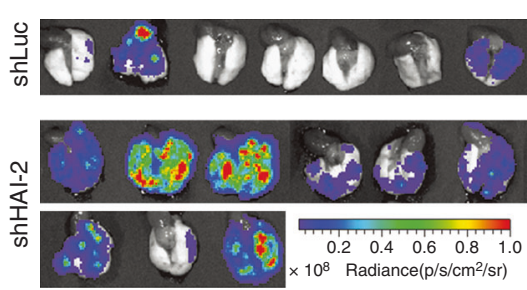

e

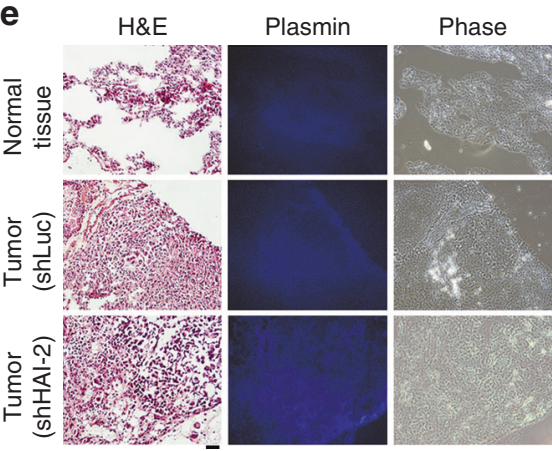

h
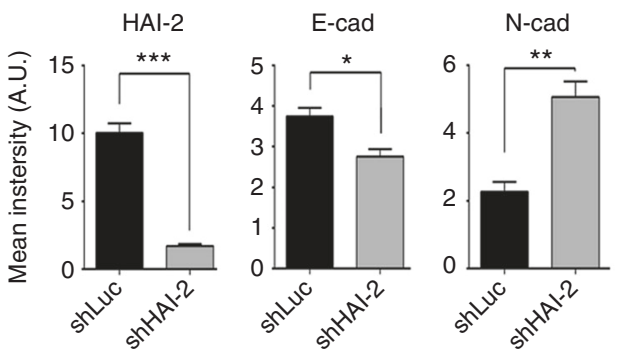

b
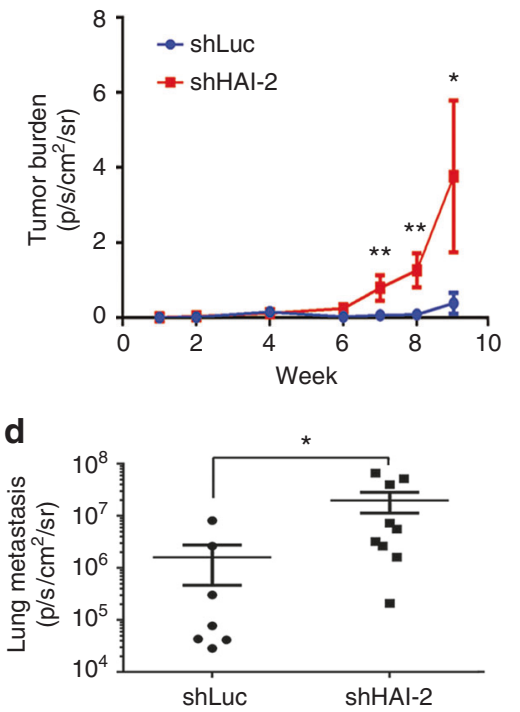

$\mathbf{f}$

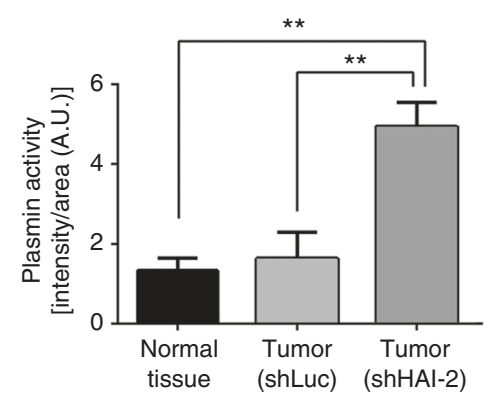

g
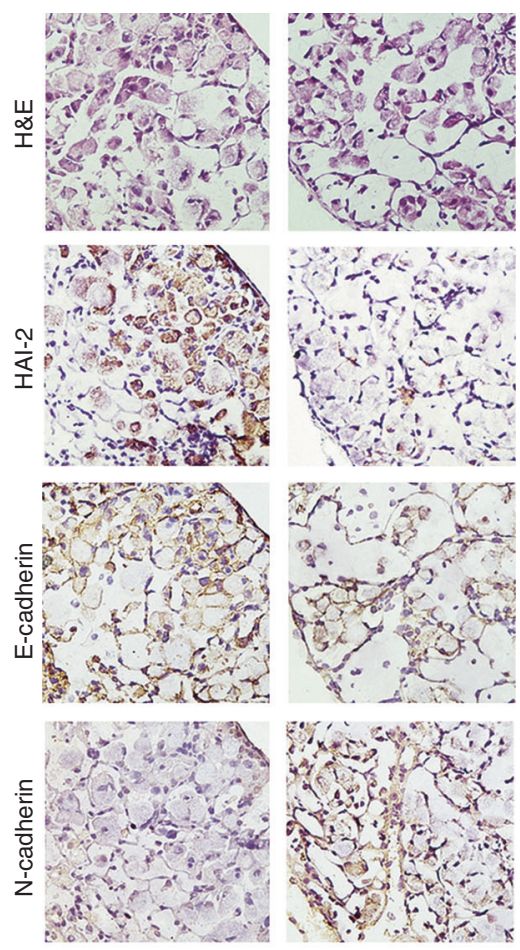

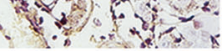

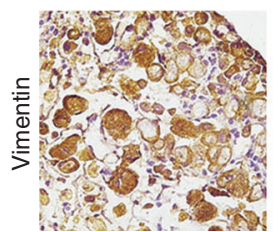

Pericellular space
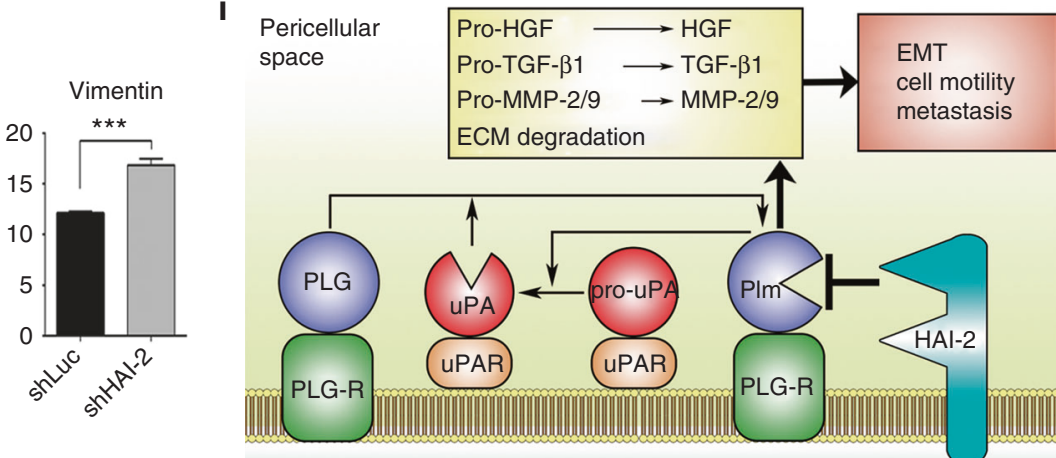

Fig. 6 Down-regulation of HAl-2 increases a lung metastatic ability of A549 cells, the tissue plasmin activity and EMT. a HAI-2-knockdown (shHAl-2) and control (shLuc) A549 cells were intravenously injected into the tail-veins of NOD/SCID mice $\left(1 \times 10^{6}\right.$ cells per mouse). The metastatic cells in mouse lungs were tracked by bioluminescence and measured by in vivo imaging system (Xenogen IVIS 50 , Perkin Elmer). The images from three representative mice in each experimental group were shown in week 1, 6 and 9 after tumour injection. $\mathbf{b}$ The intensities of bioluminescence of metastatic cells were quantified by Living Image Software and statistically calculated by GraphPad Prism 6 (mean \pm SEM., shLuc, $n=7$; shHAI-2, $n=9 ;{ }^{*} p<0.05 ;{ }^{* *} p<0.005$. Student's $t$-test). c Metastatic lesions in mouse lungs. Mice were scarified in week 10 after tumour injection and the lungs were harvested. The bioluminescence of metastatic cells was visualised by in vivo imaging system. d Quantification of metastatic lesions in mouse lungs. The bioluminescence of metastatic cells in mouse lungs was quantified and statistically calculated (mean \pm SEM., shLuc, $n=7$; shHAI-2, $n=9 ;{ }^{*} p<0.05 ;{ }^{* *} p<0.005$. Student's $t$-test). e In situ plasmin proteolytic activity in mouse lungs. The frozen sections of the mouse lung tissues covered with artificial substrates (ALK-AMC) and incubated at $37^{\circ} \mathrm{C}$ for an hour. The in situ plasmin activities were visualised by a fluorescent microscopy using UV excitation ( $360 \mathrm{~nm}$ ). H\&E: hematoxylin and eosin stain; Plasmin: in situ zymography of plasmin; Phase: phase contrast images. Scare bar $=100 \mu \mathrm{m}$. f Quantification of in situ plasmin proteolytic activity in normal and tumour tissues (mean $\pm \mathrm{SD}, n=3$; ${ }^{* *} p<0.01$; one-way ANOVA). g Immunohistochemical staining of HAI-2, E-cadherin, Ncadherin and Vimentin in the frozen sections of mouse lung tissues. Scare bar $=100 \mu \mathrm{m}$. $\mathbf{h}$ Quantification of the IHC intensity in four different tumour lesions of each experiment. The intensity of the IHC images was measured and quantified by ImageJ. $\mathbf{i}$ The model of HAI-2-repressing uPAS, EMT, cell motility and metastasis of lung adenocarcinoma 
progression. ${ }^{14,53}$ Unexpectedly, the expression levels of hepsin were decreased in the highly invasive lung adenocarcinoma (CL15 and H1299) (Supplementary Figure S2), compared to lowly invasive A549 and CL1-0 cells. The analyses of TCGA database revealed that matiptase is down-regulated in the high-risk group with a low survival rate in lung adenocarcinoma patients (Supplementary Figure S3A), while hepsin levels is not relevant with the lung cancer patients' survival (both low-risk and high-risk groups have a similar survival rate, Supplementary Figure S3B). In addition, matriptase briefly expresses in two of five lung cancer cell lines, ${ }^{54}$ and hepsin is amplified only in $5.4 \%$ cases of lung adenocarcinoma. ${ }^{53}$ The results together suggest that matriptase and hepsin may not be implicated in HAl-2 downregulationmediated lung adenocarcinoma progression. Instead, downregulation of $\mathrm{HAl}-2$ in lung adenocarcinoma could promote cell invasion and metastasis via an increase of plasmin activity. The data together indicate that $\mathrm{HAl}-2$ exhibits a distinct regulation on its target serine protease in different cancers; e.g., the HAI-2/ matriptase axis for prostate cancer ${ }^{11,39}$ versus the HAl-2/plasmin axis for NSCLC. The exact pair between HAl-2 and its specific target in the other cancers requires more investigations.

The UPA and UPA receptor (UPAR) are expressed in lung adenocarcinoma cells (Supplementary Figure S11 and ref. ${ }^{27}$ ). Moreover, two SERPIN-type inhibitors, PAI-1 and a-2-antiplasmin, have been well-studied and irreversibly inhibit uPA and plasmin activity, respectively. ${ }^{55} \mathrm{a}$-2-antiplasmin has been identified only to repress free plasmin but unable to inhibit cell-surface plasmin (Supplementary Figure S12 and ref. ${ }^{56}$ ). Interestingly, HAl-2 is newly identified to be a membrane-anchored and non-covalent inhibitor to modulate the PAS system by directly inhibiting cellsurface plasmin, leading to suppression of the PAS system. The inhibition of $\mathrm{HAl}-2$ on plasmin shows a distinct enzyme-inhibitor kinetic from a-2-antiplasmin on plasmin or PAl-1 on UPA (Supplementary Figure S13). In the presence of equimolar uPA and plasminogen, the low (1:10) and high ratios (1:1) of PAI-1 to UPA have a similar inhibitory activity on plasmin ( 60\% inhibitions), while $\mathrm{HAl}-2$ possess a dose-dependent manner to inhibit plasmin activity [ 75\% inhibition at a high ratio (10:1) of HAI-2 to uPA/plasminogen and $\sim 20 \%$ inhibition at a low ratio (1:1)] (Supplementary Figure S13A). For inhibiting plasmin, a-2antiplasmin shows a more effective suppression on plasmin ( $\sim 40 \%$ at a low ratio to plasmin, and over $99 \%$ at a high ratio), while the high ratio of HAI-2 to plasmin exhibited up to $66 \%$ inhibition (Supplementary Figure S13B). Thus, the results imply that $\mathrm{HAl}-2$ has a less inhibitory effect on plasmin than a-2antiplasmin. In NSCLC, a-2-antiplasmin has no function on cellsurface plasmin, while membrane-anchored HAI-2 serves as an important inhibitor for cell-surface plasmin to suppress the PAS system. Without HAI-2's inhibition, cell-surface plasmin becomes constitutively active for massive ECM degradation and growth factor activation, leading to invasive lung tumour growth and metastasis.

The decreased expression of HAl-2 promoted an EMT-like process in lung cancer cells. Our data manifest that UPA is required for the EMT of lung cancer cells which is induced by HAl-2 downregulation. Activation of two pro-growth factors (pro-HGF and proTGF- $\beta 1$ ) is regulated by the plasmin-HAI-2 axis. On the other hand, it had no significant effect on EGFR signalling because the administration of plasmin could not affect EGFR in the NSCLC (Supplementary Figure S14). Our clinical results showed that HAI-2 was significantly down-regulated in the lung cancer patients with high tumour invasion (T3 + T4 v.s. T1 + T2). Since EMT plays an important role in the tumour dissemination, 28 the downregulation of $\mathrm{HAl}-2$ may be a factor to promote tumour dissemination in lung adenocarcinoma via up-regulation of plasmin and the PAS. Therefore, the expression levels of HAl-2 in tumour lesions may serve as a prognostic marker to evaluate the metastatic risk of lung adenocarcinoma.
In Figs. 5e, c, the alteration folds of the EMT markers in HAI-2silencing A549 cells were not as high as the effects of $\mathrm{HAl}-2$ overexpression on those markers in $\mathrm{CL} 1-5$ cells. The discrepancy of EMT marker changes after the alteration of HAl-2 expression in CL1-5 and A549 cells may be due to the nature of cell lines, including the different levels of uPA between both cells (Supplementary Figure S11). Since CL1-5 cells have a higher level of UPA (Supplementary Figure S11) and plasminogen activation than A549 cells (20\% plasmin for CL1-5 versus $1 \%$ plasmin for A549, under a regular culture condition, Supplementary Figure S15), CL1-5 cells would be more sensitive to the alteration of HAI-2 than A549 cells. Thus, HAI-2 overexpression can efficiently repress plasmin and c-Met activity in CL1-5 cells. In A549 cells, HAI2 silencing can increase the EMT with a less degree than that of the increased MET in CL1-5 cells after HAl-2 overexpression, because of the low plasminogen activation ( 1\% plasmin) in A549 cells compared to CL1-5 cells ( 20\% plasmin, Supplementary Figure S15).

Although the previous reports have shown that only Kunitz domain 1 of HAl-2 is responsible for inhibiting HGFA, matriptase and prostate cancer cell invasion, ${ }^{39,57}$ we find that both Kunitz domains of HAI-2 can suppress plasmin activities (Supplementary Figure S16A and S16B) and cell motility (Supplementary Figure S16C and S16D) in NSCLC. Because most of NSCLC have no or a trace of matriptase expression (Supplementary Figure S2 and S10), HAl-2-mediated NSCLC cell motility and metastasis may be mainly through regulating plasmin rather than matriptase.

The cell-surface receptors for UPA and plasminogen are crucial for the activation of the PAS. In general, pro-uPA binds to UPA receptor (UPAR) for a proteolytic conversion to UPA by the cellsurface plasmin. ${ }^{58}$ In comparison with UPAR, the plasminogen receptors are miscellaneous in various cell types; ${ }^{59}$ Among them, cell-surface Cytokeratin 8 and 18 (CK8/18) have been identified to be a plasminogen receptor in cancer. ${ }^{60}$ Our data revealed that CK8/18 physically interacted with plasminogen and $\mathrm{HAl}-2$ in NSCLC (Supplementary Figure S17A S17C), and co-localised the cell surface (Supplementary Figure S17D). The pericellular locations of HAl-2 and plasminogen were also confirmed by the colocalisation with E-cadherin (Supplementary Figure S18\&S19). The data suggest that $\mathrm{CK} 8 / 18$ may function as a plasminogen receptor and cooperate with HAI-2 to modulate the PAS system in NSCLC.

In summary, this study shows a novel mechanism that HAl-2 regulates the cell-surface plasmin and functions as a potent inhibitor for the PAS system of NSCLC. The down-regulation of HAl-2 is one of the causes to promote EMT, cell invasion and metastasis. In addition, the purified recombinant HAI-2 proteins exhibit an inhibitory activity against plasmin and NSCLC invasion, suggesting a therapeutic potential of HAl-2 in targeting plasmin and suppression of NSCLC metastasis.

\section{ACKNOWLEDGEMENTS}

This study was supported by Taiwan National Science Council Grant NSC 100-2628-B002-004-MY4, Ministry of Science and Technology Grants MOST 104-2320-B-002-044MY3, MOST 105-2911-I-002-521 and MOST 106-2320-B-002-046-MY3, National Health Research Institutes Grant NHRI-EX99-9909BC, NHRI-EX104-10401BI and NHRI-EX10710725Bl, and National Taiwan University Grant NTU-CESRP-104R7602C4, NTU105R89612 and NTU107L890504 to M.S. Lee. We appreciate the service of the First Core Laboratory of National Taiwan University College of Medicine. We thank Dr. Pan-Chyr Yang at the Department of Internal Medicine, National Taiwan University Hospital, College of Medicine, National Taiwan University for his gifts of lung cancer cell lines and Dr. ChenYong Lin at the Georgetown University for his gifts of antibodies. We would like to thank Laboratory Animal Core Facility which is funded by Agricultural Biotechnology Research Center (ABRC) at Academia Sinica for their services.

\section{AUTHOR CONTRIBUTIONS}

S.R.W. carried out the major experiments and wrote the manuscript. C.H.L. initialise the project and generated the HAl-02-overepxressing CL1-05 cell line. H.P.S. 
performed the Q-PCR assay. C.J.K. and H.Y.L. performed the animal experiments. S.W. L. and H.H.L. were responsible for IHC staining. H.F.T. contributed to immunofluorescent staining. H.P.H. and C.C.H. gave comments for clinical data and IHC scoring. M. S.L. designed the project and edited the manuscript. All authors commented on the manuscript.

\section{ADDITIONAL INFORMATION}

Supplementary information is available for this paper at https://doi.org/10.1038/ s41416-019-0400-2.

\section{Competing interests: The authors declare no competing interests.}

Ethics approval and consent to participate: This study was approved by National Taiwan University Hospital Institutional Review Board (IRB \#200903072 R). All human tissues are provided by US Biomax Inc. and collected under HIPPA approved protocols. The donors are informed completely with their consent. The study was performed in accordance with the Declaration of Helsinki.

Note: This work is published under the standard license to publish agreement. After 12 months the work will become freely available and the license terms will switch to a Creative Commons Attribution 4.0 International (CC BY 4.0).

Publisher's note: Springer Nature remains neutral with regard to jurisdictional claims in published maps and institutional affiliations.

\section{REFERENCES}

1. Molina, J. R., Yang, P., Cassivi, S. D., Schild, S. E. \& Adjei, A. A. Non-small cell lung cancer: epidemiology, risk factors, treatment, and survivorship. Mayo Clin. Proc. 83, 584-594 (2008).

2. Torre, L. A., Siegel, R. L. \& Jemal, A. Lung Cancer Statistics. Adv. Exp. Med. Biol. 893, 1-19 (2016).

3. Duffy, M. J. The role of proteolytic enzymes in cancer invasion and metastasis. Clin. Exp. Metastas-. 10, 145-155 (1992)

4. Ludwig, T. Local proteolytic activity in tumor cell invasion and metastasis. Bioessays 27, 1181-1191 (2005).

5. Shimomura, T. et al. Hepatocyte growth factor activator inhibitor, a novel Kunitztype serine protease inhibitor. J. Biol. Chem. 272, 6370-6376 (1997).

6. Marlor, C. W. et al. Identification and cloning of human placental bikunin, a novel serine protease inhibitor containing two Kunitz domains. J. Biol. Chem. 272, 12202-12208 (1997).

7. Parr, C. \& Jiang, W. G. Hepatocyte growth factor activation inhibitors (HAI-1 and HAI-2) regulate HGF-induced invasion of human breast cancer cells. Int. J. Cancer 119, 1176-1183 (2006).

8. Delaria, K. A. et al. Characterization of placental bikunin, a novel human serine protease inhibitor. J. Biol. Chem. 272, 12209-12214 (1997).

9. Tung, E. K. et al. HAl-2 is epigenetically downregulated in human hepatocellular carcinoma, and its Kunitz domain type 1 is critical for anti-invasive functions. Int. J. Cancer 124, 1811-1819 (2009).

10. Dong, W., Chen, X., Xie, J., Sun, P. \& Wu, Y. Epigenetic inactivation and tumor suppressor activity of HAl-2/SPINT2 in gastric cancer. Int. J. Cancer 127, 1526-1534 (2010)

11. Tsai, C. H. et al. HAl-2 suppresses the invasive growth and metastasis of prostate cancer through regulation of matriptase. Oncogene 33, 4643-4652 (2014).

12. Hwang, S. et al. Epigenetic silencing of SPINT2 promotes cancer cell motility via HGF-MET pathway activation in melanoma. J. Invest. Dermatol. 135, 2283-2291 (2015).

13. Nakamura, K., Hongo, A., Kodama, J. \& Hiramatsu, Y. The role of hepatocyte growth factor activator inhibitor (HAl)-1 and HAl-2 in endometrial cancer. Int. J. Cancer 128, 2613-2624 (2011).

14. Kirchhofer, D. et al. Hepsin activates pro-hepatocyte growth factor and is inhibited by hepatocyte growth factor activator inhibitor-1B (HAl-1B) and HAI-2. FEBS Lett. 579, 1945-1950 (2005).

15. Ulisse, S., Baldini, E., Sorrenti, S. \& D'Armiento, M. The urokinase plasminogen activator system: a target for anti-cancer therapy. Curr. Cancer Drug. Targets 9 , 32-71 (2009).

16. Andreasen, P. A., Egelund, R. \& Petersen, H. H. The plasminogen activation system in tumor growth, invasion, and metastasis. Cell. Mol. Life Sci. 57, 25-40 (2000).

17. Hildenbrand, R., Allgayer, H., Marx, A. \& Stroebel, P. Modulators of the urokinasetype plasminogen activation system for cancer. Expert. Opin. Investig. Drugs 19, 641-652 (2010).
18. Petersen, L. C. Kinetics of reciprocal pro-urokinase/plasminogen activation-stimulation by a template formed by the urokinase receptor bound to poly(Dlysine). Eur. J. Biochem. 245, 316-323 (1997).

19. Deryugina, E. I. \& Quigley, J. P. Cell surface remodeling by plasmin: a new function for an old enzyme. J. Biomed. Biotechnol. 5, 642-659 (2012).

20. Kwaan, H. C. \& McMahon, B. The role of plasminogen-plasmin system in cancer. Cancer Treat. Res. 148, 43-66 (2009).

21. Davis, G. E., Pintar Allen, K. A., Salazar, R. \& Maxwell, S. A. Matrix metalloproteinase-1 and 9 activation by plasmin regulates a novel endothelial cell-mediated mechanism of collagen gel contraction and capillary tube regression in three-dimensional collagen matrices. J. Cell. Sci. 114(Pt 5), 917-930 (2001).

22. Mars, W. M., Zarnegar, R. \& Michalopoulos, G. K. Activation of hepatocyte growth factor by the plasminogen activators UPA and tPA. Am. J. Pathol. 143, 949-958 (1993).

23. Naldini, L. et al. Biological activation of pro-HGF (hepatocyte growth factor) by urokinase is controlled by a stoichiometric reaction. J. Biol. Chem. 270, 603-611 (1995).

24. Yee, J. A., Yan, L., Dominguez, J. C., Allan, E. H. \& Martin, T. J. Plasminogendependent activation of latent transforming growth factor beta (TGF beta) by growing cultures of osteoblast-like cells. J. Cell. Physiol. 157, 528-534 (1993).

25. Mazar, A. P. The urokinase plasminogen activator receptor (UPAR) as a target for the diagnosis and therapy of cancer. Anticancer Drugs 12, 387-400 (2001).

26. Salden, M. et al. The urokinase-type plasminogen activator system in resected non-small-cell lung cancer. Rotterdam Oncology Thoracic Study Group. Ann. Oncol. 11, 327-332 (2000).

27. Lu, J. J. et al. Prognostic value of urokinase plasminogen activator system in nonsmall cell lung cancer: a systematic review and meta-analysis. Mol. Clin. Oncol. 8, 127-132 (2018).

28. Banyard, J. \& Bielenberg, D. R. The role of EMT and MET in cancer dissemination. Connect. Tissue Res. 56, 403-413 (2015).

29. Wheelock, M. J., Shintani, Y., Maeda, M., Fukumoto, Y. \& Johnson, K. R. Cadherin switching. J. Cell. Sci. 121(Pt 6), 727-735 (2008)

30. Mendez, M. G., Kojima, S. \& Goldman, R. D. Vimentin induces changes in cell shape, motility, and adhesion during the epithelial to mesenchymal transition. FASEB J. 24, 1838-1851 (2010).

31. Lamouille, S., Xu, J. \& Derynck, R. Molecular mechanisms of epithelialmesenchymal transition. Nat. Rev. Mol. Cell Biol. 15, 178-196 (2014).

32. Shih, J. Y. \& Yang, P. C. The EMT regulator slug and lung carcinogenesis. Carcinogenesis 32, 1299-1304 (2011).

33. Wasilko, D. J. et al. The titerless infected-cells preservation and scale-up (TIPS) method for large-scale production of NO-sensitive human soluble guanylate cyclase (sGC) from insect cells infected with recombinant baculovirus. Protein Expr. Purif. 65, 122-132 (2009).

34. Yen, H. Y. et al. Effect of sialylation on EGFR phosphorylation and resistance to tyrosine kinase inhibition. Proc. Natl. Acad. Sci. USA 112, 6955-6960 (2015)

35. Wei, T. T. et al. Induction of c-Cbl contributes to anti-cancer effects of HDAC inhibitor in lung cancer. Oncotarget 6, 12481-12492 (2015).

36. Phelps, R. M. et al. NCl-Navy Medical Oncology Branch cell line data base. J. Cell. Biochem. Suppl. 24, 32-91 (1996).

37. Giard, D. J. et al. In vitro cultivation of human tumors: establishment of cell lines derived from a series of solid tumors. J. Natl. Cancer Inst. 51, 1417-1423 (1973).

38. Lai, Y. J. et al. N-glycan branching affects the subcellular distribution of and inhibition of matriptase by HAl-2/placental bikunin. PLoS One 10, e0132163 (2015).

39. Wu, S. R. et al. The Kunitz domain I of hepatocyte growth factor activator inhibitor- 2 inhibits matriptase activity and invasive ability of human prostate cancer cells. Sci. Rep. 7, 15101 (2017).

40. Chu, Y. W. et al. Selection of invasive and metastatic subpopulations from a human lung adenocarcinoma cell line. Am. J. Respir. Cell Mol. Biol. 17, 353-360 (1997).

41. Aguirre-Gamboa, R. et al. SurvExpress: an online biomarker validation tool and database for cancer gene expression data using survival analysis. PLoS One 8, e74250 (2013)

42. Palmer, T. D., Ashby, W. J., Lewis, J. D. \& Zijlstra, A. Targeting tumor cell motility to prevent metastasis. Adv. Drug Deliv. Rev. 63, 568-581 (2011).

43. Shi, X. \& Jarvis, D. L. Protein N-glycosylation in the baculovirus-insect cell system. Curr. Drug. Targets 8, 1116-1125 (2007).

44. Sun, Z. et al. The blockage of the high-affinity lysine binding sites of plasminogen by EACA significantly inhibits prourokinase-induced plasminogen activation. Biochim. Biophys. Acta 1596, 182-192 (2002).

45. Monea, S., Lehti, K., Keski-Oja, J. \& Mignatti, P. Plasmin activates pro-matrix metalloproteinase-2 with a membrane-type 1 matrix metalloproteinasedependent mechanism. J. Cell. Physiol. 192, 160-170 (2002).

46. Hsu, T. I. et al. Sp1 expression regulates lung tumor progression. Oncogene 31, 3973-3988 (2012) 
47. Farrell, J. et al. HGF induces epithelial-to-mesenchymal transition by modulating the mammalian hippo/MST2 and ISG15 pathways. J. Proteome Res. 13, 2874-2886 (2014).

48. Shanmukhappa, K., Matte, U., Degen, J. L. \& Bezerra, J. A. Plasmin-mediated proteolysis is required for hepatocyte growth factor activation during liver repair. J. Biol. Chem. 284, 12917-12923 (2009).

49. Liu, F. et al. HGF induces EMT in non-small-cell lung cancer through the hBVR pathway. Eur. J. Pharmacol. 811, 180-190 (2017).

50. Xu, J., Lamouille, S. \& Derynck, R. TGF-beta-induced epithelial to mesenchymal transition. Cell Res. 19, 156-172 (2009).

51. Katsuno, Y., Lamouille, S. \& Derynck, R. TGF-beta signaling and epithelialmesenchymal transition in cancer progression. Curr. Opin. Oncol. 25, 76-84 (2013).

52. Khalil, N., Corne, S., Whitman, C. \& Yacyshyn, H. Plasmin regulates the activation of cell-associated latent TGF-beta 1 secreted by rat alveolar macrophages after in vivo bleomycin injury. Am. J. Respir. Cell Mol. Biol. 15, 252-259 (1996).

53. Tang, X. et al. Targeted inhibition of cell-surface serine protease Hepsin blocks prostate cancer bone metastasis. Oncotarget 5, 1352-1362 (2014).
54. Jin, X. et al. Production of soluble matriptase by human cancer cell lines and cell surface activation of its zymogen by trypsin. J. Cell. Biochem. 95, 632-647 (2005).

55. Robbie, L. A., Booth, N. A., Croll, A. M. \& Bennett, B. The roles of alpha 2antiplasmin and plasminogen activator inhibitor 1 (PAI-1) in the inhibition of clot lysis. Thromb. Haemost. 70, 301-306 (1993).

56. Hall, S. W., Humphries, J. E. \& Gonias, S. L. Inhibition of cell surface receptorbound plasmin by alpha 2-antiplasmin and alpha 2-macroglobulin. J. Biol. Chem. 266, 12329-12336 (1991).

57. Qin, L., Denda, K., Shimomura, T., Kawaguchi, T. \& Kitamura, N. Functional characterization of Kunitz domains in hepatocyte growth factor activator inhibitor type 2. FEBS Lett. 436, 111-114 (1998).

58. Smith, H. W. \& Marshall, C. J. Regulation of cell signalling by uPAR. Nat. Rev. Mol. Cell Biol. 11, 23-36 (2010).

59. Miles, L. A., Plow, E. F., Waisman, D. M. \& Parmer, R. J. Plasminogen receptors. J. Biomed. Biotechnol. 2012, 130735 (2012).

60. Weng, Y. R., Cui, Y. \& Fang, J. Y. Biological functions of cytokeratin 18 in cancer. Mol. Cancer Res. 10, 485-493 (2012). 